\title{
Water sorption on coal: effects of oxygen-containing function groups and pore structure
}

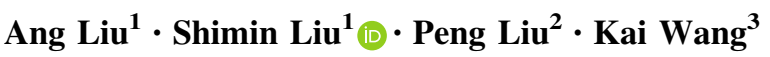

Received: 30 November 2020/Revised: 23 January 2021 / Accepted: 21 March 2021/Published online: 28 April 2021

(C) The Author(s) 2021

\begin{abstract}
Coal-water interactions have profound influences on gas extraction from coal and coal utilization. Experimental measurements on three coals using X-ray photoelectron spectroscopy (XPS), low-temperature nitrogen adsorption and dynamic water vapor sorption (DVS) were conducted. A mechanism-based isotherm model was proposed to estimate the water vapor uptake at various relative humidities, which is well validated with the DVS data. The validated isotherm model of sorption was further used to derive the isosteric heat of water vapor sorption. The specific surface area of coal pores is not the determining parameter that controls water vapor sorption at least during the primary adsorption stage. Oxidation degree dominates the primary adsorption, and which togethering with the cumulative pore volume determine the secondary adsorption. Higher temperature has limited effects on primary adsorption process. The isosteric heat of water adsorption decreases as water vapor uptake increases, which is found to be close to the latent heat of bulk water condensation at higher relative humidity. The results confirmed that the primary adsorption is controlled by the stronger bonding energy while the interaction energy between water molecules during secondary adsorption stage is relatively weak. However, the thermodynamics of coal-water interactions are complicated since the internal bonding interactions within the coal are disrupted at the same time as new bonding interactions take place within water molecules. Coal has a shrinkage/swelling colloidal structure with moisture loss/gain and it may exhibit collapse behavior with some collapses irreversible as a function of relative humidity, which further plays a significant role in determining moisture retention.
\end{abstract}

Keywords Water vapor · Isotherm · Surface oxidation · Pore collapse - Isosteric heat of adsorption

Publisher's Note Springer Nature remains neutral with regard to jurisdictional claims in published maps and institutional affiliations.

Shimin Liu

szl3@psu.edu

1 Department of Energy and Mineral Engineering, G3 Center and Energy Institute, The Pennsylvania State University, University Park, PA 16802, USA

2 State Key Laboratory of Coal Mine Disaster Dynamics and Control, Chongqing University, Chongqing 400030, China

3 School of Emergency Management and Safety Engineering, China University of Mining and Technology (Beijing), Beijing 100083, China

\section{Introduction}

Water is the most common solvent in nature. The properties of water have been extensively investigated in many scientific disciplines such as chemistry, biology, geology (Fan and Ma 2018; Li et al. 2018; Fan et al. 2019; Smith et al. 2019), nanotechnology and materials technology (Furmaniak et al. 2008). Water naturally co-exists within coal formation as geological processes apply pressure to dead biotic material over time. Water retention in coal seam can also result from reservoir stimulation using water-based fracturing fluids (Huang et al. 2019a, b; Yang and Liu 2020). The resultant water blocking effects because of permanent water-soaking during hydraulic fracturing process exerts a potential risk for reservoir 
damage and contamination (Tang et al. 2017). In addition, water retention in coal has significant influences on coal utilization including pyrolysis, gasification, liquefaction and combustion (Yu et al. 2013). The interaction of coal with retained water is a complex and intricate process compared to gas-coal interactions (Wang et al. 2017; Liu et al. 2020a, b, c), such as methane, nitrogen, or carbon dioxide (Liu et al. 2020d), which is mainly due to the weak dispersion interaction of water with coal. The complex interactions include formations of hydrogen bonds among water molecules, surface chemical species interactions, and the chemisorptive interaction with the coal mineral matter (Busch and Gensterblum 2011). Unfortunately, the fundamental understandings of water retention behavior, water sorption and transport behaviors, and water-blocking pattern in carbonaceous coal are still largely unknown.

The water adsorption isotherm on coal has been historically studied in the literatures (Allardice and Evans 1971; Mahajan and Walker 1971; Joubert et al. 1974; Kaji et al. 1986; McCutcheon et al. 2003; Charrière and Behra 2010; Busch and Gensterblum 2011; Švábová et al. 2011). It is generally believed that the combination of weak carbonwater dispersive attractions and strong water-water associative interactions is the controlling factor for the complex behavior of confined water in coal (Furmaniak et al. 2008). In other words, the heterogeneity of coal surface (i.e.polar oxygen-containing groups e.g. carboxyl $(-\mathrm{COOH})$, carbonyl $(\mathrm{C}=\mathrm{O})$, and hydroxyl $(-\mathrm{OH}))$ and those active sites usually lead to the primary adsorption through H-bonds formation Fig. 1a (Kadioğlu and Varamaz 2003; Ahamed et al. 2019). Water molecules strongly adsorbon hydrophilic sites provided by oxygen functional groups on the surfaces of coal and mineral matter. This is followed by the secondary adsorption that results in the formation of water clusters and eventually pore filling (Fig. 1b, c) (Furmaniak et al. 2008; Ahamed et al. 2019).

In this study, the proposed model for quantifying the combination of the primary and secondary adsorption is the main innovation. The modeled primary and secondary adsorption capacities can be theoretically separated which are expected to be further linked with the surface chemistry controlling the primary adsorption and pore properties influencing secondary adsorption. In addition, the ClausiusClapeyron equation is the widely used model to calculate the isosteric heat. But it should be noted that the ClausiusClapeyron equation is a vapor pressure-based model. For water vapor sorption on different sorptive materials, it is much more reasonable to link the isosteric heat with the sorption capacity (i.e. water content). Therefore, the improved model for quantifying the relative isosteric heat of water sorption on coal was derived based on the proposed isotherm model of water sorption. We experimentally measured dynamic water vapor sorption for selected coal and employed X-rays Photoemission Spectroscopy (XPS) and low-pressure nitrogen adsorption to characterize the oxygen-containing functional groups and pore structure modifications. The proposed analytical model was validated against the water vapor sorption isotherms on three coal samples measured at three different temperatures 25 , 30 and $35{ }^{\circ} \mathrm{C}$, respectively. The validated model was used to distinguish the contributions of primary and secondary sorption to the apparent water vapor sorption. The relationships between water vapor sorption capacity and the surface chemistry of coal through X-ray photoelectron spectroscopy (XPS) and pore structure properties of coal (low-temperature nitrogen adsorption) were discussed in detail. These results provide mechanism-based method for analyzing the water sorption behavior and coal-water interactions with potential application of CBM development (Liu et al. 2018) and coal utilization.
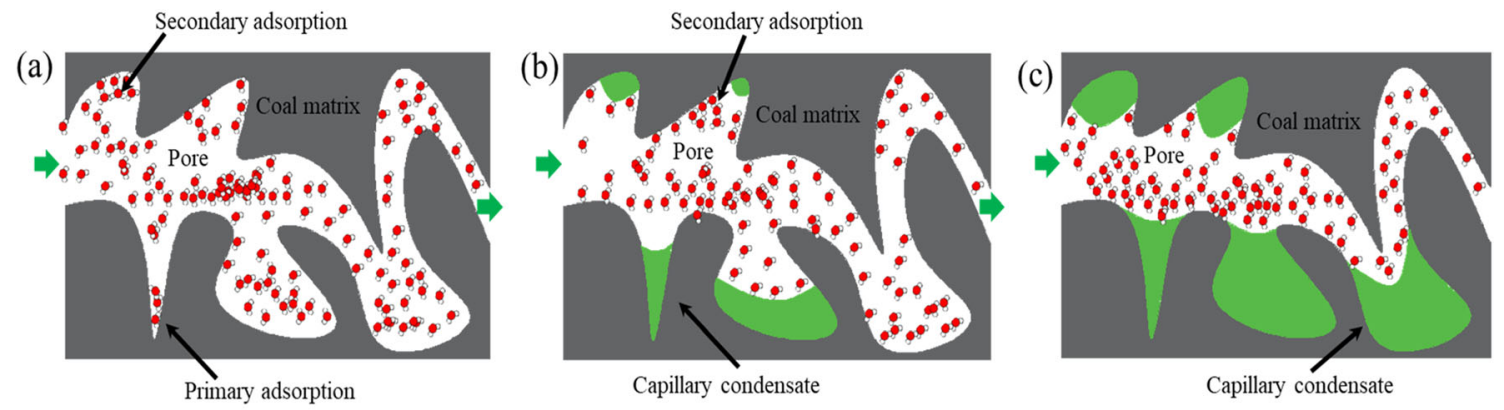

Relative Humidity

Fig. 1 Schematic of water vapor adsorption mechanisms on coal (modified from Sang et al. (2019)). a Primary adsorption on hydrophilic sites induced by monolayer adsorption dominates at low relative humidity level. b and $\mathbf{c}$ Secondary adsorption dominates at high relative humidity including formation of multilayer adsorption and capillary condensation. 


\section{Background and previous studies}

A linear relationship between the water holding capacity and the amount of oxygen functional groups was experimentally observed, proving that the oxygen-containing functional groups are the active sites for water vapor sorption (Kaji et al. 1986). It was experimentally observed that the coal rank was an important factor that influences the amount of oxygen functional groups in coal (van Krevelen 1993). The experimental data showed that the hydroxyl groups were abundant in brown coal and were predominant with phenolic compounds, followed by the carboxyl groups and methoxy groups $\left(-\mathrm{OCH}_{3}\right)$. The experimental data also showed that the carbonyl groups can be found in lignite and brown coals but which were in negligible amounts (van Krevelen 1993)- the results were in line with other investigations (Schafer 1970; Murata et al. 2000; Giroux et al. 2006). Although the functional groups have slight variation in the trend following with coal rank, the abundance of oxygen-containing functional groups increases towards to low rank coals and enhances the hydrophilicity of coal surfaces to increase the water holding capacity (Stach 1982; Ogunsola 1993; Murata et al. 2000; Ahamed et al. 2019).

The presence of oxygen functional groups influences water vapor adsorption mainly at low vapor pressure. The carboxylic groups and hydroxyl groups are the most preferred hydrophilic sites for water adsorption (Ahamed et al. 2019). These preferred oxygen functional groups act as primary adsorption sites for water molecules through hydrogen bonds (Švábová et al. 2011). Water molecules attached to the primary sites form the secondary adsorption sites on which the water aggregates or clusters can be formed. The clusters accumulate and eventually form into large clusters. The growth of these clusters at the opening of the pores can effectively become a plug to block the entire pore channel (Brennan et al. 2001). As water vapor pressure increases, the continuous pore filling can essentially occur. The standard Type II sigmoid shape of water sorption isotherms for bed-moist Yallourn brown coal was reported based on the Brunauer, Deming, Deming and Teller classification (Allardice and Evans 1971). The sigmoid shape can be generally attributed to the combined effects of three separate sorption processes including monolayer sorption, multilayer condensation and capillary condensation (Allardice and Evans 1971).

Additionally, the mineral matters and pore size distribution in coals have important influences on water vapor sorption. The majority of mineral matters in coal are clay minerals and quartz (Ward 2002, 2016). It is reported that the dominant mineral quartz in coal is unreactive even at high temperature, and the interaction between quartz and water can be ignored (Ahamed et al. 2019). Kaolinite, illite, illite/smectite mixed layers and smectite minerals (i.e. montmorillonite) are the most abundant clay minerals in coal seams (Susilawati and Ward 2006; Ward 2016).The exchangeable cations dissolved in the water are preferred to be attracted if the clay platelets are negatively charged and it will lead to structural layer expansion. Compared to the smectite minerals, the kaolinite clay mineral is vulnerable to swelling (Tiwari and Ajmera 2011). The difference in the swelling magnitudes of smectite minerals and other clay minerals mainly attributes to the different swelling mechanisms (Bolt 1956). As water sorption induced clay mineral swelling can modify the pore structure of coal and its associated mineral clusters. This structural alteration, in turn, is expected to have an important role on the water adsorption of coal. However, the coal swelling with respect to the clay minerals is no less important in the coal material itself, which was confirmed by comparing with the pore volumes of coals (from lignite to anthracite) determined by mercury porosimetry and water uptake capacities, the measurements showed that the adsorbed water contents in coals were about 2-3 times as their pore volumes would indicate (Kaji et al. 1986). It could be reasonably postulated that the physical change on coal structure of coal-water system as a function of relative humidity plays significant role in determining moisture retention behavior. An important question to be addressed in this study is how moisture retention capacity and the phenomenon of collapse of coal structure are related.

The above mechanisms behind the physicochemical reactions within coal-water interactions provide the physical understanding of water sorption, pore filling and water condensation, based on which the quantitative evaluation of water uptake amount is essential for engineering application. Many sorption-related models were proposed in the past century. The Langmuir-type adsorption model leads the explanation of the mechanism of monolayer adsorption is very attractive and often improved (Langmuir 1916). The assumption of monolayer adsorption is widely applied, especially for gas adsorption. For water adsorption, the existence of multilayer adsorption exceeds the description range of Langmuir type equation. The Brunauer-EmmettTeller (BET) model is often used to fit the water vapor adsorption isotherm (Brunauer et al. 1938). The BET multilayer sorption model assumes that the secondary adsorption centers exhibit lower binding energies and the thermodynamic properties of the secondary adsorbed water are identical with those of liquid water (Charrière and Behra 2010). But the goodness of fitting results between water vapor uptake and relative humidity based on BET model was found to fail if the relative humidity ranges from 0.35 to higher values. Later, the BET model has been modified and improved by taking two sorption sites into 
account and better fitting results were arrived (Charrière and Behra 2010). The most classical extension of the BET model is the GAB model (Anderson 1946; de Boer 1953; Guggenheim 1966), which is applicable over a more broad range of relative humidity. The difference between the BET and GAB models is that an additional parameter was introduced into the latter one. The parameter represents the potential of multilayer molecules relative to the potential of bulk liquid (Sang et al. 2019). The DubininSerpinsky (DS) approach provided a phenomenological model of adsorption of water molecules on primary and the secondary adsorption sites. The DS sorption theory assumes that water molecules firstly adsorb on energy privileged centers (i.e. oxygen functional groups) and those adsorbed molecules are capable of providing secondary adsorption centers for water-water interactions through hydrogen bonds (Dubinin et al.1955). However, one drawback of the DS model is that its assumption lacks of saturation of the secondary adsorption centers (Furmaniak et al. 2008). In addition, there were many other semi-empirical and theoretical models proposed in recent years, which were comprehensively summarized in review publications (Furmaniak et al. 2008; Liu et al. 2017).

In terms of thermodynamic theory, it is considered that water vapor adsorption is an exothermic process (Charrière and Behra 2010). The Clausius-Clapeyron equation theoretically defines the isosteric enthalpy of adsorption and the isosteric heat of adsorption depends on the surface chemistry and the pore structure. The isosteric heat of water adsorption was reported to have values very close to the latent heat of bulk water condensation $-45 \mathrm{~kJ} / \mathrm{mol}$ at a surface coverage up to $10 \%$ (Busch and Gensterblum 2011). Busch et al. concluded that the isosteric heat ofsorption is higher than the heat of condensation when functional groups are present and it was suggested that carbon-water interaction was weak if the isosteric enthalpy of adsorption was low with high surface coverage (Busch and Gensterblum 2011). The first isosteric enthalpy of adsorption corresponds to the modified DS equation was derived by Kraehenbuehl et al. based on the ClausiusClapeyron equation (Kraehenbuehl et al. 1986). In 1958, Darcey reported that the heat of adsorption on Saran charcoals was $63 \mathrm{~kJ} / \mathrm{mol}$ for a surface coverage of only $1 \%$, whereas the heat of adsorption approaches the heat of water condensation of $45 \mathrm{~kJ} / \mathrm{mol}$ at about $5 \%$ surface coverage (Dacey et al. 1958; Mahajan 1991). The Clausius-Clapeyron equation assumes the isosteric heat of sorption is independent of temperature. The net isosteric heat of sorption can be derived based on the ClausiusClapeyron equation and the total differentiation of adsorption isotherm with respect to temperature at a constant moisture content - the net isosteric heat of sorption is the difference between the isosteric heat and pure water vaporization energy (Furmaniak et al. 2008; Charrière and Behra 2010; Švábová et al. 2011; Wan et al. 2016). Subsequently, the temperature-dependent and water vapor uptake dependence model of isosteric heat was proposed based on the Dent's multilayer adsorption model (Tang et al. 2017). Based on this model, it was found that the ideal gas law would result in an overestimation of the isosteric heat of adsorption at high vapor pressure conditions.

\section{Material and methods}

\subsection{Sample collection and preparation}

Two Illinois coals were collected from Herrin seam and Springfield seam and the central Appalachian basin seam was taken from Pocahontas seam. For denotation purpose, we termed Springfield coal as IL-C\#1(sub-bituminous coal), Herrin coal as IL-C\#2 (sub-bituminous coal) and the central Appalachian basin coal as AB-C (low volatile bituminous coal). Prior to the test, the prepared samples were kept in an environmental chamber under controlled conditions of temperature and humidity equilibration.

\subsection{XPS measurements}

XPS is a quantitative and reliable technique using X-rays to remove electrons from the $\mathrm{C} 1 \mathrm{~s}$ and $\mathrm{O} 1 \mathrm{~s}$ levels of coal sample (Kovtun et al. 2019). The energies of the emitted electrons depend on the atoms present and the chemical composition of thematerial. This allows the quantification of elemental composition in the parts-per-thousand range as well as the nature of the chemical bonds. XPS can thus provide a measure of surface oxidation degree through the $\mathrm{O} / \mathrm{C}$ ratio, quantify the different types of carbon functionalities present on the coal, indicate the formation of chemical bonds, and evaluate the physisorption of molecules (Behm 2016; Zaldivar et al. 2017). XPS experiments were performed using a Physical Electronics VersaProbe II instrument equipped with a monochromatic $\mathrm{Al} \mathrm{k} \alpha \mathrm{X}$-ray source $(\mathrm{h} v=1486.7 \mathrm{eV})$ and a concentric hemispherical analyzer. Charge neutralization was performed using both low energy electrons $(<5 \mathrm{eV})$ and argon ions. The binding energy axis was calibrated using sputter cleaned $\mathrm{Cu}(\mathrm{Cu}$ $\left.2 \mathrm{p}_{3 / 2}=932.62 \mathrm{eV}, \mathrm{Cu} 3 \mathrm{p}_{3 / 2}=75.1 \mathrm{eV}\right)$ and Au foils $(\mathrm{Au}$ $\left.4 \mathrm{f}_{7 / 2}=83.96 \mathrm{eV}\right)$. Peaks were charge referenced to $\mathrm{CH} x$ band in the carbon $1 \mathrm{~s}$ spectra at $284.5 \mathrm{eV}$ (Seah 2001). Measurements were made at a takeoff angle of $45^{\circ}$ with respect to the sample surface plane. This resulted in a typical sampling depth of 3-6 nm (95\% of the signal originated from this depth or shallower). Quantification was done using instrumental relative sensitivity factors 
(RSFs) that account for the X-ray cross section and inelastic mean free path of the electrons. Data analysis and fitting were performed with CasaXPS software authorized in MCL at The Pennsylvania State University.

\subsection{Low-pressure liquid nitrogen adsorption}

The low-temperature nitrogen adsorption (LTNA) test at $77 \mathrm{~K}$ was performed on three coal samples (60-80 mesh) using a Micrometrics TriStar II 3020 Version 2.0 using the static volumetric method. Prior to the test, all the prepared coal samples were degassed under vacuum at $200{ }^{\circ} \mathrm{C}$ for at least $12 \mathrm{~h}$. After degassing, the degassed sample is exposed to $\mathrm{N}_{2}$ at $-196{ }^{\circ} \mathrm{C}$ in a relative pressure $\left(p / p_{0}\right)$ ranging from 0.001 to 0.995 , where $p$ is the equilibrium pressure and $p_{0}$ is the saturation pressure. The pore properties including the specified surface area (SSA), pore volumes (PV) and pore size distribution (PSD) were defined by combining the standard Brunauer-Emmett-Teller (BET) model and density functional theory (Gregg and Sing 1982; Sang et al. 2018).

\subsection{Dynamic water vapor sorption}

To determine the water holding capacity of coal different relative humidity, a commonly used approach is the static vapor sorption test by using salt solutions generating different relative humidity (Pan et al. 2010; Babu and Sathian 2011; Crosdale et al. 2008, Van and Campbell 2002). The Dynamic Vapor Sorption (DVS) Intrinsic is designed to accurately measure the mass changes of sample under different relative humidities. The instrument used is shown in Fig. 2. The mechanism behind the DVS instrument is a gravimetric method-based ultra-sensitive recording microbalance. The ultra-sensitive recording microbalance is capable of measuring changes in sample mass with the accuracy of $1 \mathrm{ppm}$. As the air with a known relative humidity passes over the sample, the changes in the mass sample are continuously recorded. In Fig. 2, the DVS instrument contains three main parts including the reservoir chamber, sample chamber and the balance chamber. Relative humidity is the ratio of the partial vapor pressure to the saturation vapor pressure of water at a given temperature. Relative humidity is generated by accurately mixing dry (dry $\mathrm{N}_{2}$ stream) and saturated vapor gas flows (wetting $\mathrm{N}_{2}$ stream containing $100 \%$ humidity) in the proportional mixture, using precision mass flow controllers. The relative humidity sensor and temperature probe located in the sample chamber are used to verify system performance. In sample chamber, the sample is loaded on sample pan under the given temperature. The gas flow with required relative humidity from the reservoir chamber passes over the sample and the changes in the sample mass occur as time increases due to water uptake. The changes in sample mass are continuously monitored and recorded by the data acquisition system. It should be noted that there is an additional temperature probe and an air purge in the balance chamber. To ensure the accurate performance of the ultra-sensitive recording microbalance apart from the potential condensation of water vapor in the balance chamber, the dry purge gas with a fixed flow rate of 70 sccm and a temperature of $40{ }^{\circ} \mathrm{C}$ is continuously flowed.

In this study, the isotherms of water vapor sorption on coals are targeted to be obtained under various relative humidities and temperatures (i.e. $25^{\circ} \mathrm{C}, 30^{\circ} \mathrm{C}$ and 35 $\left.{ }^{\circ} \mathrm{C}\right)$. The raw sample weights of IL-C\#1, IL-C\#2 and AB-C are $30.68,35.06$, and $38.83 \mathrm{mg}$, respectively. The water vapor adsorption and desorption processes were measured in the relative humidity ranges from 0 to 0.95 and then back to 0 after one complete cycle. In Fig. 3 , the raw data recovered from the DVS analyzer for IL-C\#1was plotted. Under initial dry condition $\left(R_{\mathrm{h}} \sim 0 \%\right)$, any residual water can be removed until a constant value which is the sample mass (Sang et al. 2019). The equilibrium state under different relative humidities is defined when mass change is less than or equal to $0.002 \%$ per minute and maintained stable for 10 minutes. The average of the last three points was taken as the final equilibrium value. Water vapor adsorption/desorption isotherms are then directly computed from the difference between the reference mass and the equilibrium mass at any prescribed relative humidity.

\section{Water vapor sorption modeling}

\subsection{Water vapor sorption isotherms}

Previous studies showed that the difference in the shape of water vapor sorption isotherms is caused by the combined effects of primary and secondary adsorptions (Busch et al. 2011; Kaji et al. 1986; McCutcheon et al. 2003; Murata et al. 2000; Nishino 2001). Water vapor is presumed to be firstly and directly adsorbed on the primary sorption sites in the presence of hydrophilic functional groups due to their strong binding energy with water molecules. Subsequently, those adsorbed water molecules occupied on primary sites are considered as the secondary centers for the formation of water aggregates or clusters. For the simplification of modeling water vapor isotherm, it is assumed that the secondary adsorption starts only after the monomolecular coverage is achieved during the primary adsorption stage.

The Langmuir model, leading to the explanation of the mechanism of adsorbate sorption behavior (Langmuir 1916). For the application of Langmuir-type model, the surface of adsorbent is assumed as homogeneous and there is a maximum surface concentration of adsorbate adsorbed on adsorbent in monolayer pattern. An additional 


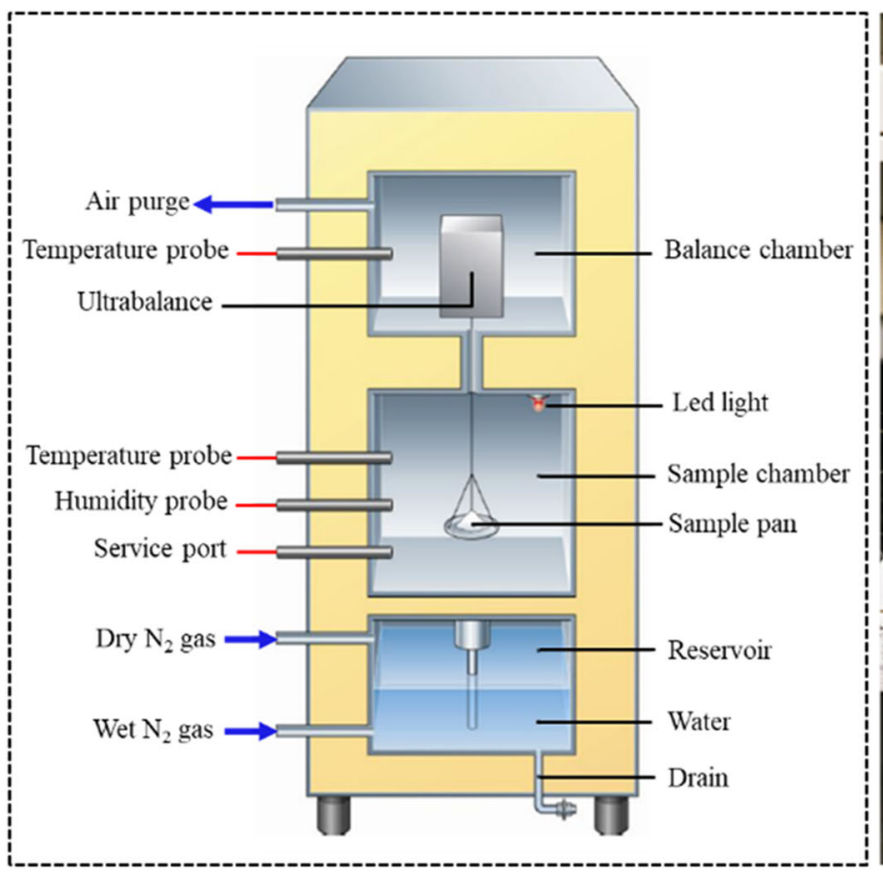

(a)

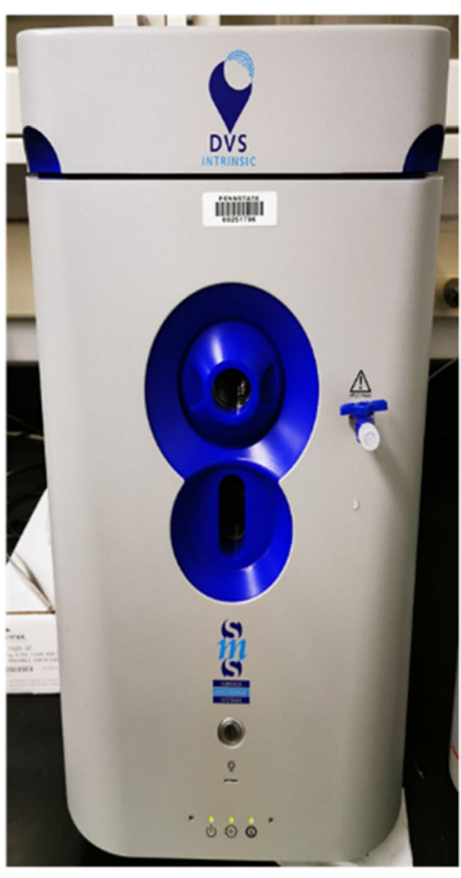

(b)

Fig. 2 Schematic and lab-view of the DVS instrument

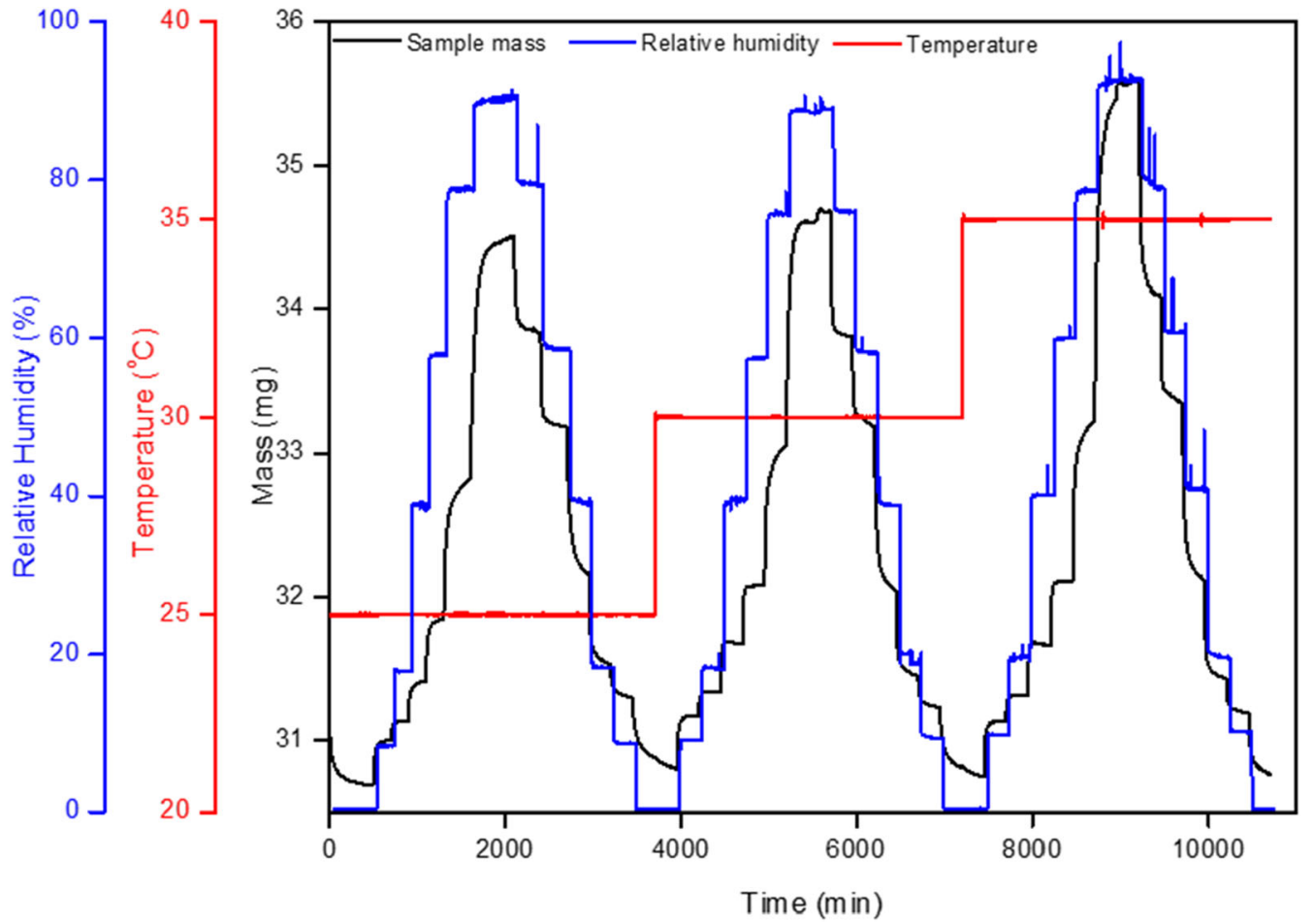

Fig. 3 Three full circles of water vapor sorption measurements - raw data from DVS instrument dynamic vapor sorption analyzer for IL-C\#1

assumption is that adsorption sites are identical and mutually independent, and each site can accommodate only one molecule. Thus, the Langmuir-type model is appropriate to describe the process of the monomolecular coverage with the increase in water vapor pressure, the Langmuir-type sorption model for water vapor sorption at specified relative humidity can be introduced and expressed as (Langmuir 1916; Furmaniak et al. 2008) 
$m_{\mathrm{pri}}=\frac{m_{\mathrm{L}} R_{\mathrm{h}}}{R_{\mathrm{L}}+R_{\mathrm{h}}}$

where, $m_{\text {pri }}$ is the primary adsorption of water vapor at specified relative humidity, $\mathrm{mmol} / \mathrm{g} ; m_{\mathrm{L}}$ is the maximum water vapor uptake corresponding to a complete monolayer coverage, $\mathrm{mmol} / \mathrm{g} ; R_{\mathrm{L}}$ is the relative humidity at which the measured adsorption content is equal to $1 / 2 m_{\mathrm{L}}$, dimensionless.

For the secondary adsorption, the phenomenological Dubinin-Serpinsky approach was introduced to accommodate the formation of water aggregates or clusters on energy privileged sites acting as primary adsorption centers for water on predominantly hydrophobic carbon surface. The Dubinin-Serpinsky model can be written as (Dubinin et al. 1955)

$m_{\mathrm{sec}}=\frac{m_{0} c k R_{\mathrm{h}}}{1-c k R_{\mathrm{h}}}$

where, $m_{\mathrm{sec}}$ is the secondary adsorption of water vapor at specified relative humidity, $\mathrm{mmol} / \mathrm{g} ; m_{0}$ is the surface concentration of the energy privileged hydrophilic adsorption centres, $\mathrm{mmol} / \mathrm{g} ; c$ is the ratio between the rate constants of adsorption and desorption, dimensionless; $k$ represents the loss of the secondary sites in the course of adsorption, dimensionless, which is a constant whose magnitude is fixed by the condition that for $R_{\mathrm{h}}=1$. In the original Dubinin-Serpinsky model, $k$ is treated as a part of $c$ and is equal to unity (Furmaniak et al. 2008). It should be noted that the parameter is also regarded as unity in this study.

Ideally, all the primary adsorbed water molecules can become the secondary adsorption centers and are available for multilayer formation of water aggregates or clusters. In other words, the water vapor uptake of the energy privileged hydrophilic adsorption centers $\left(m_{0}\right)$ in Eq. (2) can be regarded as the primary adsorption of water vapor calculated from Langmuir-type adsorption model $\left(m_{\text {pri }}\right)$ (Eq. (1)). However, previous studies showed that not all the water molecules can be considered as the secondary adsorption centers for the formation of water clusters mainly due to the mechanical constraints to pore structure, swelling or steric effects (Barton et al. 1994). Therefore, the parameter " $\omega$ " was introduced to accommodate the non-perfectly multilayer formation building from the monomolecular coverage (Furmaniak et al. 2008)- the water vapor uptake of the energy privileged hydrophilic adsorption centers $\left(m_{0}\right)$ can be calculated from $m_{0}=\omega m_{\text {pri }}$, where $0 \leq \omega \leq 1$. Totally, the isothermal curve of water vapor sorption over the entire range of relative humidity is summation of the primary adsorption and secondary adsorption and mathematically it can be expressed as

$m=m_{\mathrm{pri}}+m_{\mathrm{sec}}=\frac{m_{\mathrm{L}} R_{\mathrm{h}}\left(1-c R_{\mathrm{h}}+c \omega R_{\mathrm{h}}\right)}{\left(R_{\mathrm{L}}+R_{\mathrm{h}}\right)\left(1-c R_{\mathrm{h}}\right)}$

where, $\omega$ is the ratio of the amount of primary adsorption centers involved in the formation of the secondary adsorption centers, dimensionless. It can be seen that if all the adsorbed molecules on primary centers can be treated as the secondary centers $(\omega=1)$, Eq. (3) can be reduced to the generalized D'Arcy-Watt model (Furmaniak et al. 2008). The GAB model is an extension of the classical BET model if the constant $c$ is taken as unity. Based on the water adsorption isotherm measured on oxidized nanoporous carbon, Barton et al. found that only $17 \%$ of the primary sites can be performing as the secondary centers (Babu and Sathian 2011). However, others suggested that those water molecules adsorbed at the primary sites can form up bonds for the formation of microclusters consisting of two to three molecules (Crosdale et al. 2008; Van and Campbell 2002). Furmaniak et al. summarized that the values of $\omega$ can be lower than unity or can be close to three for carbonaceous materials (Furmaniak et al. 2008). In this study, $\omega$ is regarded as unity which is a rational assumption. Thus, we proposed the model by assuming all the adsorbed water molecules through primary adsorption can provide new sorption centers for the formation of water clusters.

\subsection{Isosteric heat of water vapor adsorption}

The adsorption heat of water vapor indicates that adsorption is a strong function of surface chemistry. If the isosteric heat of water vapor adsorption is assumed as independence of temperature, the Clausius-Clapeyron equation defines the isosteric heat of adsorption as

$$
\frac{\Delta H}{R T^{2}}=\left[\frac{\partial \ln (p)}{\partial T}\right]_{m}
$$

where, $\Delta H$ is the isosteric enthalpy of water vapor adsorption at a specific water content $(\mathrm{mmol} / \mathrm{g})$ - the subscript $m$ represents the given water content, $\mathrm{kJ} / \mathrm{mol} ; p$ is the equilibrium water vapor pressure, $\mathrm{kPa} ; R$ is the universal gas constant, $\mathrm{J} /(\mathrm{mol} \mathrm{K}) ; T$ is the temperature, $\mathrm{K}$.

The water adsorption isotherm, Eq. (3), written in the form with respect to water vapor pressure, can be expressed as:

$m=\frac{m_{\mathrm{L}} p\left(p_{0}-c p+c \omega p\right)}{\left(p_{0} R_{\mathrm{L}}+p\right)\left(p_{0}-c p\right)}$

where, $p_{0}$ is the saturated pressure of water vapor at given temperature, $\mathrm{kPa}$. 
Taking the logarithm on both sides of Eq. (5) and then taking the total differentiation of which with respect to temperature at a constant moisture content, gives:

$0=\frac{\partial \ln \left(\frac{m_{\mathrm{L}} p}{p_{0} R_{\mathrm{L}}+p}\right)}{\partial T}+\frac{\partial \ln \left(\frac{p_{0}-c p+c \omega p}{p_{0}-c p}\right)}{\partial T}$

By taking the derivation of $\ln p$ with respect to $T$ following mathematical principals, then simplifying and rearranging the terms gives:

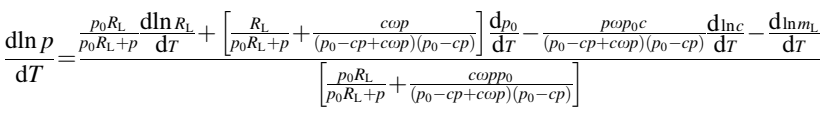

In Eq. (7), the saturated water vapor pressure $\left(p_{0}\right)$ is a temperature-dependent parameter. The August-RocheMagnus formula provides a very good approximation to calculate the saturated water vapor pressure (Alduchov et al., 1996):

$p_{0}=0.61094 \exp \left(\frac{17.625 T-4814.269}{T-30.11}\right)$

where, $p_{0}$ is the saturated water vapor pressure, $\mathrm{kPa} ; T$ is temperature, $K$.

The temperature-dependent parameter $c$ plays an important role in the description of the shape of the water adsorption isotherm. Kraehenbuehl et al. have derived the relationship between immersion calorimetry and the temperature-dependent parameter $c$, which can be expressed as (Kraehenbuehl et al. 1986):

$c=c_{0} \exp \left(q_{0} / R T\right)$

where, $c_{0}$ is the experimental fitting parameter, dimensionless; $q_{0}$ is enthalpy of immersion into water, $\mathrm{kJ} / \mathrm{mol}$.

The temperature-dependent parameter $R_{\mathrm{L}}$ plays an important role in the description of the shape of the water adsorption isotherm:

$R_{\mathrm{L}}=R_{\mathrm{L} 0} \exp \left(q_{\mathrm{L}} / R T\right)$

where, $q_{\mathrm{L}}$ is the adsorption energy on primary sites, $\mathrm{kJ} /$ mol; $R_{\mathrm{L} 0}$ is the experimental fitting parameter, dimensionless.

By taking the differentiationsof Eqs. (8) and (9) with respect to temperature, and then substituting them into Eq. (7), yields:

$\frac{\mathrm{d} \ln p}{\mathrm{~d} T}=\frac{\frac{p_{0} R_{\mathrm{L}}}{p_{0} R_{\mathrm{L}}+p} \frac{\mathrm{d} \ln R_{\mathrm{L}}}{\mathrm{d} T}+\left[\frac{R_{\mathrm{L}} p_{0}}{p_{0} R_{\mathrm{L}}+p}+\frac{c \omega p p_{0}}{\left(p_{0}-c p+c \omega p\right)\left(p_{0}-c p\right)}\right] \frac{4283.58}{(T-30.11)^{2}}-\frac{p \omega p_{0} c q_{0}}{\left(p_{0}-c p+c \omega p\right)\left(p_{0}-c p\right) R T^{2}}-\frac{\mathrm{d} \ln m_{\mathrm{L}}}{\mathrm{d} T}}{\left[\frac{p_{0} R_{\mathrm{L}}}{p_{0} R_{\mathrm{L}}+p}+\frac{c \omega p p_{0}}{\left(p_{0}-c p+c o p\right)\left(p_{0}-c p\right)}\right]}$

By introducing Eq. (11) into Eq. (4), and then inserting Eqs. (8), (9) and (10) into Eq. (11), yields:
$\Delta H=\frac{\frac{p_{0} R_{\mathrm{L}} q_{\mathrm{L}}}{p_{0} R_{\mathrm{L}}+p}+\left[\frac{R_{\mathrm{L}} p_{0}}{p_{0} R_{\mathrm{L}}+p}+\frac{c \omega p p_{0}}{\left(p_{0}-c p+c \omega p\right)\left(p_{0}-c p\right)}\right] \frac{4283.58 R T^{2}}{(T-30.11)^{2}}+\frac{p \omega p_{0} c q_{0}}{\left(p_{0}-c p+c \omega p\right)\left(p_{0}-c p\right)}-\frac{\mathrm{d} \ln m_{\mathrm{L}}}{\mathrm{d} T}}{\left[\frac{p_{0} R_{\mathrm{L}}}{p_{0} R_{\mathrm{L}}+p}+\frac{c \omega p p_{0}}{\left(p_{0}-c p+c \omega p\right)\left(p_{0}-c p\right)}\right]}$

Equation (12) gives the expression for calculating the isosteric heat of water vapor adsorption. Previous studies shown that the term $\frac{\mathrm{d} \ln m_{\mathrm{L}}}{\mathrm{d} T}$ is very small and which can be ignored (Wan et al. 2016).

By ignoring the term $\frac{\mathrm{d} \ln m_{\mathrm{L}}}{\mathrm{d} T}$, on the right side of Eq. (12), the simplified model for calculating the isosteric heat of water vapor adsorption can be expressed as:

$\Delta H=\frac{\frac{p_{0} R_{\mathrm{L}} q_{\mathrm{L}}}{p_{0} R_{\mathrm{L}}+p}+\left[\frac{R_{\mathrm{L}} p_{0}}{p_{0} R_{\mathrm{L}}+p}+\frac{c \omega p p_{0}}{\left(p_{0}-c p+c \omega p\right)\left(p_{0}-c p\right)}\right] \frac{4283.58 R T^{2}}{(T-30.11)^{2}}+\frac{p \omega p_{0} c q_{0}}{\left(p_{0}-c p+c \omega p\right)\left(p_{0}-c p\right)}}{\left[\frac{p_{0} R_{\mathrm{L}}}{p_{0} R_{\mathrm{L}}+p}+\frac{c \omega p p_{0}}{\left(p_{0}-c p+c \omega p\right)\left(p_{0}-c p\right)}\right]}$

\section{Results and discussions}

\subsection{Experimental results}

\section{$5.1 .1 \mathrm{O} / \mathrm{C}$ values}

To evaluate the surface hydrophilicity of coal matrix of three coal samples, the atom ratios of oxygen to carbon $(\mathrm{O} /$ C) determined by XPS to represent the degrees of surface oxidation as suggested by previous studies (Behm 2016; Zaldivar et al. 2017; Kovtun et al. 2019). Strictly, 'oxygen atom' in this sense means that the oxygen atoms embed into the oxygen-containing functional groups such as $-\mathrm{OH}$, $-\mathrm{COOH}, \mathrm{C}=\mathrm{O}, \mathrm{C}-\mathrm{O}-\mathrm{C}$, and others. The XPS results were summarized in Table 1. Based on the XPS results, both the two Illinois coal samples contained $\mathrm{C}, \mathrm{O}, \mathrm{N}$ and $\mathrm{S}$ as well as various mineral-related elements including $\mathrm{Al}, \mathrm{Si}$ and Fe, while the central Appalachian coal sample only contained $\mathrm{C}, \mathrm{O}$, and $\mathrm{S}$ elements. The contents of carbon element in samples IL-C\#1 and IL-C\#2 show slight difference-as $\sim 71.6 \%$ and $\sim 70.2 \%$, respectively, while the sample AB-C has extremely high content of carbon, which is up to $\sim 96 \%$. The differences in the carbon contents between the sub-bituminous samples (IL-C\#1 and IL-

Table 1 Concentration of elements detected (in atom \%)

\begin{tabular}{lllllllll}
\hline Sample & $\mathrm{C}$ & $\mathrm{N}$ & $\mathrm{O}$ & $\mathrm{Si}^{\dagger}$ & $\mathrm{SO}_{4}{ }^{2-}$ & $\mathrm{R}-\mathrm{S}$ & $\mathrm{S}^{\text {total }}$ & $\mathrm{O} / \mathrm{C}^{*}$ \\
\hline IL-C\#1 & 71.6 & 1.9 & 20.7 & 1.8 & 1.5 & 2.5 & 4.0 & 0.13 \\
IL-C\#2 & 70.2 & 1.6 & 22.9 & 2.6 & 0.9 & 1.8 & 2.7 & 0.18 \\
$\mathrm{AB}-\mathrm{C}$ & 96.0 & - & 3.8 & - & - & - & 0.2 & 0.04
\end{tabular}

${ }^{\dagger}$ Samples also contained $\sim 1 \% \mathrm{Al}$ and $\sim 0.5 \% \mathrm{Fe} . \mathrm{O} / \mathrm{C}$ value of IL$\mathrm{C \# 1}=\left(20.7-4 * 1.5\left(\mathrm{SO}_{4}{ }^{2-}\right)-2 * 1.8(\mathrm{Si})-1.5(\mathrm{Al} \& \mathrm{Fe})\right) / 71.6 ; \mathrm{O} / \mathrm{C}$ value of $\mathrm{IL}-\mathrm{C \# 2}=\left(22.9-4 * 0.9\left(\mathrm{SO}_{4}{ }^{2-}\right)-2 * 2.6(\mathrm{Si})-1.5(\mathrm{Al} \& \mathrm{Fe})\right) / 70.2 ; \mathrm{O} / \mathrm{C}$ value of $\mathrm{AB}-\mathrm{C}=3.8 / 96$. 
$\mathrm{C \# 2}$ ) and low volatile bituminous coal sample (AB-C) are expected due to the degree of coalification. Due to the difference of coal ranks from lignite to anthracite, the coalification process can change the buried plant matter to an ever denser, drier, more carbon rich coal macerals. There has no $\mathrm{N}$ element was detected in AB-Csample while IL-C\#1 and IL-C\#2 have $1.9 \%$ and $1.6 \%$, respectively. Sulfur was present in IL-C\#1 and IL-C\#2 as a mixture of R-S and sulfate. The oxygen contents in IL-C\#1 and IL-C\#2 are $\sim 20.7 \%$ and $22.9 \%$, respectively, while in AB-C it only contains $3.8 \%$ oxygen elements. It should be noted that contents of oxygen elements in all coal samples do not solely attributed from the presence of oxygen-containing functional groups. As shown in Table 1, oxygen elements present in inorganic matters such as $\mathrm{SO}^{2-}, \mathrm{SiO}_{2}$ should not be counted. By subtracting the oxygen atoms contained in these inorganic matters, the values of $\mathrm{O} / \mathrm{C}$ ratio representing the surface oxidation degrees were shown in Table 1. The results shown that IL-C\#2 has the highest oxidation degree (0.18) among the three samples, followed by IL-C\#1 (0.13), which is about 4.5 times than AB-C does (0.04).

\subsubsection{Pore size distribution and pore volume for three tested coals}

Based on the low temperature nitrogen adsorption results, the nitrogen adsorption isotherms for all the tested coal samples were shown in Fig. 4. A distinctive difference in their nitrogen sorption capacities mainly results from their different physicochemical properties such as the surface chemistry property, surface area, pore size distribution, and pore volume et al. According to the IUPAC classification, all the three samples exhibit an H3-type hysteresis loop suggesting the process of capillary

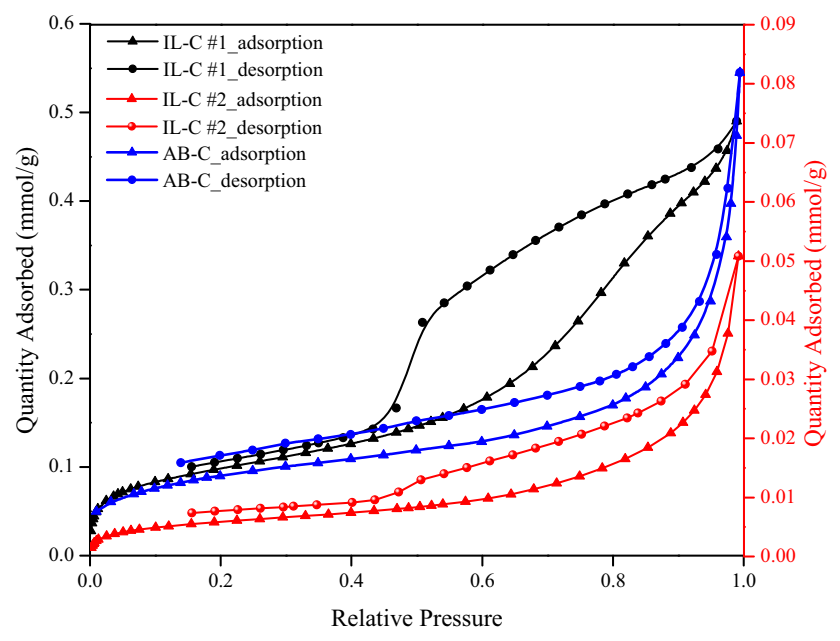

Fig. 4 Low-temperature nitrogen adsorption isotherms condensation and evaporation within the mesopores, which may suggest the contained slit-shape pores in coals (Sang et al. 2018).

Based on the nitrogen adsorption data, the PSD, specified surface area (SSA), and the cumulative pore volume are quantified based on the BET model and the density functional theory (Fig. 5a and b). In Fig. 5a, mesopores in the range $1 \mathrm{~nm}$ to $100 \mathrm{~nm}$ were well developed in IL-C\#1. The IL-C\#2 and AB-C samples have the similar PSDs. In Fig. $5 \mathrm{~b}$, the cumulative pore volumes for the three samples were measured to be $0.0137 \mathrm{~cm}^{3} / \mathrm{g}, 0.0014 \mathrm{~cm}^{3} / \mathrm{g}$ and 0.002 $\mathrm{cm}^{3} / \mathrm{g}$. IL-C\#1 has the largest cumulative pore volume for pore sizes in the range $1 \mathrm{~nm}$ to $100 \mathrm{~nm}$, which is about 6.85 times than AB-C sample does. Results of SSA show that IL-C\#1 has the highest SSA $\left(8.032 \mathrm{~m}^{2} / \mathrm{g}\right)$, followed by IL$\mathrm{C \# 2}\left(0.490 \mathrm{~m}^{2} / \mathrm{g}\right)$ and AB-C $\left(1.120 \mathrm{~m}^{2} / \mathrm{g}\right)$. The effects of the cumulative pore volumes and SSA on water vapor adsorption are compared and discussed in Sect. 5.2.1.
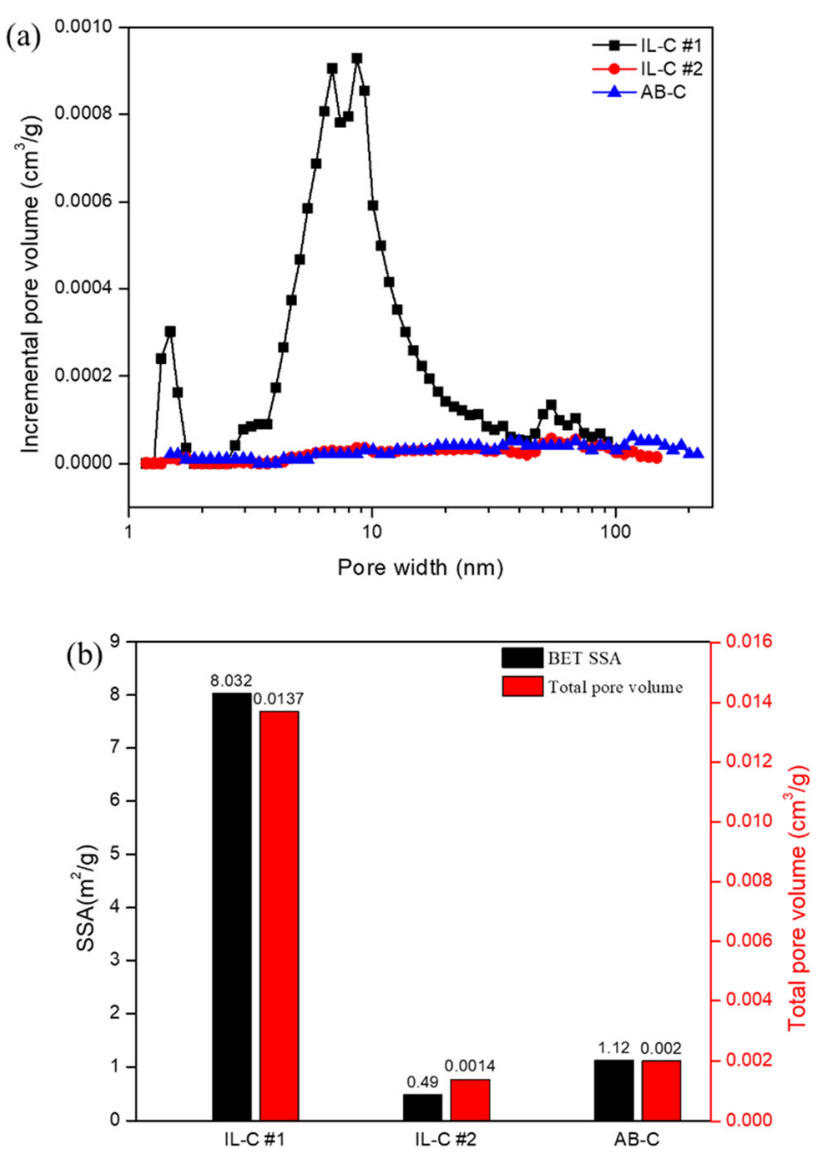

Fig. 5 Poreproperties based on BET model and density functional theory. a Pore size distribution and b SSA and cumulative pore volume 


\subsubsection{Dynamic vapor sorption isotherms}

The adsorption/desorption isotherms for the three coal samples at $25{ }^{\circ} \mathrm{C}, 30{ }^{\circ} \mathrm{C}$ and $35^{\circ} \mathrm{C}$ were plotted in Fig. 6 . According to the IUPAC classification (Thommes et al. 2015), the type II sorption isotherms were observed on all three coals. In Fig. 6a1, b1 and c1, the amounts of water vapor uptakes continuously increase with the increase in relative humidity at all given temperatures. Under the same
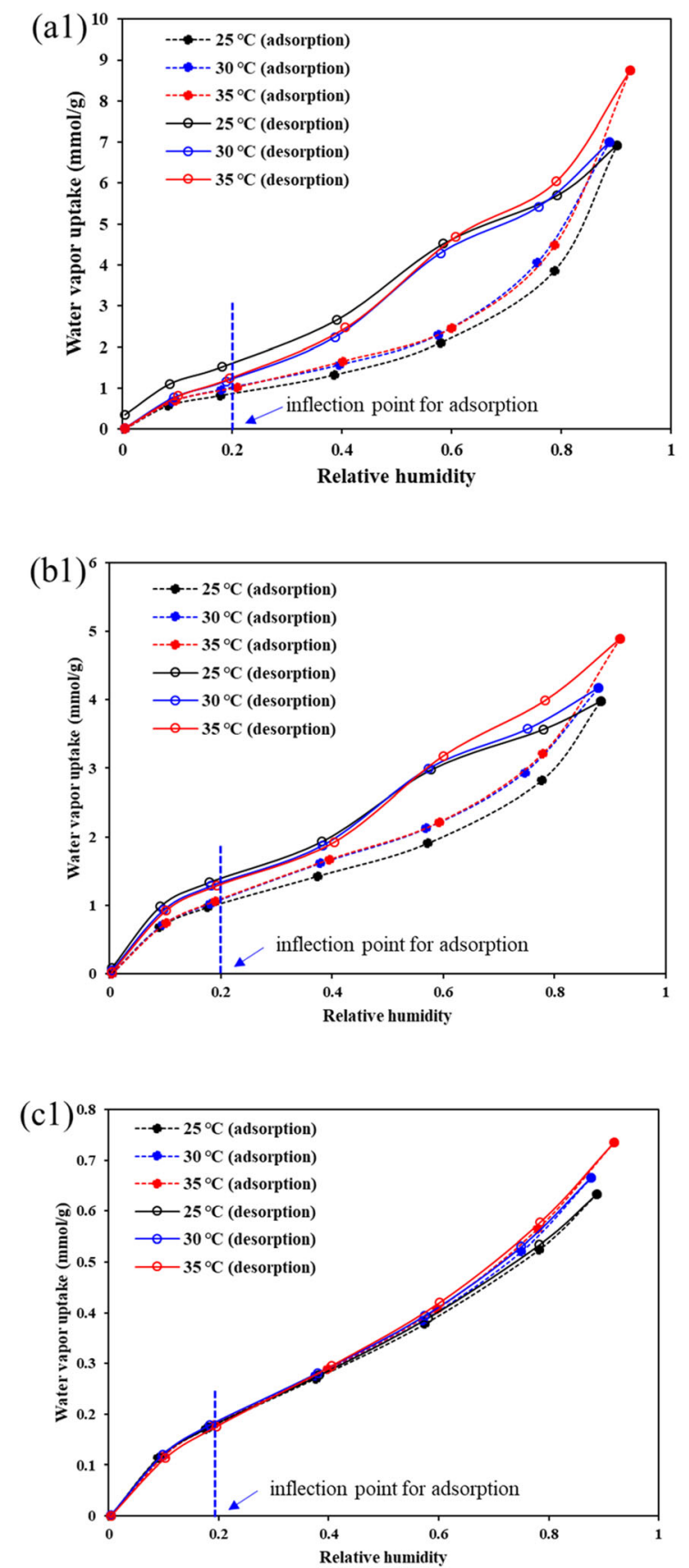

temperature, it can be observed that IL-C\#1 has the highest water holding capacity, followed by IL-C\#2 in the same order of magnitude, while the AB-C sample has the lowest water holding capacity. It can be roughly estimated that the amount of water uptake of AB-C sample is about ten times less than the two Illinois basin samples. As the increase of relative humidity, two bending regions were observed over the entire sorption isotherms. This is shown as the amount of water vapor uptake nonlinearly increases in a convex
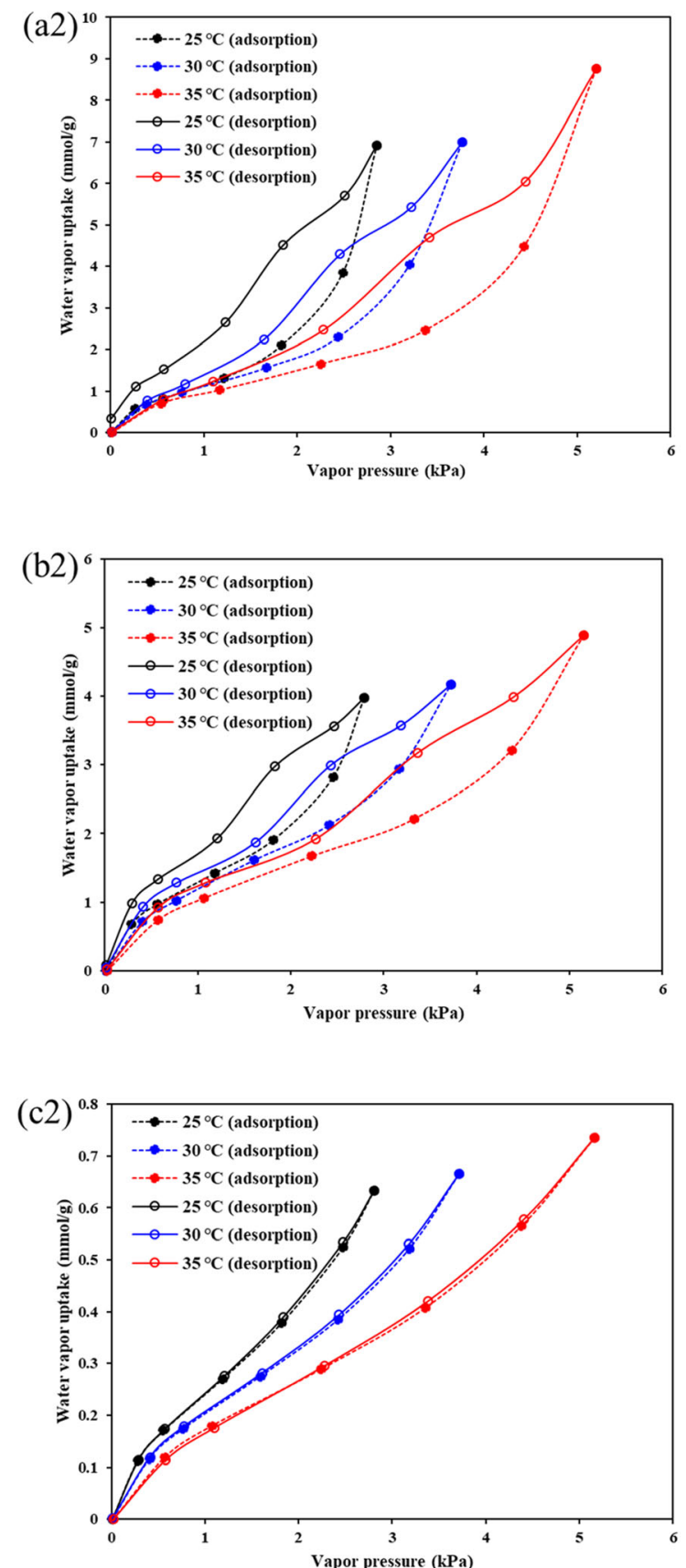

Fig. 6 Water adsorption/desorption isotherms with respect to relative humidity/vapor pressure: a1 and a2 IL-C\#1 sample; b1 and b2 IL-C\#2 sample; c1 and c2 AB-C sample 
shape at relatively low relative humidity, followed by the concave increasing trend at high relative humidity (Fig. 6). Interestingly, even the total amounts of water vapor uptakes of IL-C\#1 and IL-C\#2 show distinctive difference, the presences of the inflection points do not show obvious differences with both occurring at the relative humidity of $\sim 0.2$. Additionally, the inflection point for AB-C sample also occurs at around relative humidity of $\sim 0.2$, but the corresponding amount of water vapor uptake at this point is about ten times less than the other two samples. Previous studies shown that the shape of the isotherm is the combination of monolayer adsorption on primary adsorption sites, followed by the secondary adsorption on sites provided by primary adsorbed water molecules (Allardice and Evans 1971). Among the possible mechanism-based factors influencing the primary and secondary adsorption processes including mineral components, coal rank, surface chemistry and pore properties et al., the oxygen-containing functional groups and the pore properties were quantified in Sects. 5.1.1 and 5.1.2. As shown in Table 1, the results showed that the oxidation degrees of IL-C\#1 and IL-C\#2 show slight difference for $\mathrm{O} / \mathrm{C}$ ratio with 0.13 and 0.18 , respectively. But both IL coals have much higher $\mathrm{O} / \mathrm{C}$ ratios than that of AB-C sample of value at 0.04. In Sect. 5.1.2, the results determined from the low temperature nitrogen adsorption shown that IL-C\#1 has obviously developed pore network than IL-C\#2 while the latter one has similar pore network as AB-C sample.

Temperature is an important factor impacts water vapor adsorption, but the difference is not obvious by plotting the sorption isotherms with respect to relative humidity (Fig. 6a1, b1 and c1). The isotherms of water vapor uptake with respect to vapor pressures at different temperatures were plotted in Fig. 6a2, b2 and c3. The temperature has negative effect on the adsorption uptake resulting in a higher adsorption uptake at lower temperature. Theoretically, as the increase of vapor temperature, the movement activities of water molecules are expected to be elevated and water molecules should have enough energy to get rid of intermolecular attraction forces between the sorption sites and water molecules. However, temperature makes only subtle difference to the isotherms at relatively low relative humidity and the difference at higher relative humidity is much apparent as data indicated in Fig. 6. As illustrated in Fig. 7, the hydrogen bonds can be formed between the water molecules with the oxygen-containing functional groups mainly during the primary adsorption stage (Fig. 7b). With the increase in relative humidity, the hydrogen bonds can also be formed between the free water vapor molecules and the primary adsorbed water molecules (Fig. 7a and b), but the bonding energy is relatively weak by comparing with the energy of hydrogen bonds within the primary adsorption. Thus, the temperature effects can be interpreted as the stronger binding energy between water molecule and coal surface (Type II) than the attraction energy between water molecules (Type I) in Fig. 7a. The higher temperature increases the energy of water molecules, which may overcome the attraction energy between water molecules during secondary adsorption period, but may not overcome the energy barrier induced by binding energy between water molecule and oxygen-containing functional groups on the surface of coal matrix.

\subsection{Modeling results and discussions}

\subsubsection{Adsorption isotherms of considering both primary adsorption and secondary adsorption}

Based on the experimental results, the isotherm model, combing both primary adsorption (Eq. (1)) and secondary adsorption (Eq. (2)), was proposed as Eq. (3). The parameters, $m_{\mathrm{L}}$ and $R_{\mathrm{L}}$, are quantified to evaluate the water vapor uptake induced by the primary adsorption and the parameter $c$ is involved to characterize the secondary adsorption process. Based on Eq. (3), the modeled results agree well against with the experiment data with $R^{2}>0.99$ (Fig. 8a1, b1 and c1), and the fitting results are listed in Table 2. Based on the fitted results of $m_{\mathrm{L}}, R_{\mathrm{L}}$ and $c$, the contributions of primary and secondary adsorption to the entire adsorption isotherm were calculated and plotted in Fig. 8a2, b2 and c2. In addition, the effects of temperature on primary and secondary adsorptions were evaluated through the changes of corresponding parameters $m_{\mathrm{L}}, R_{\mathrm{L}}$ and $c$. Based on the fitting results, the questions raised in last section about the effects of oxidation degree and pore properties on primary and secondary adsorption and whether these factors can affect the sorption stages in different order can be mechanistically discussed and revealed.

The parameters $m_{\mathrm{L}}$ based on the Langmuir-type primary adsorption representing the maximum water vapor uptake corresponding to a complete monolayer coverage. We first examined the modeling results of the two sub-bituminous coals from Illinois Basin. Under the same temperature, taking $25{ }^{\circ} \mathrm{C}$ or example, the primary adsorption capacity of IL-C\#2 $(\sim 1.090 \mathrm{mmol} / \mathrm{g})$ is slightly higher than ILC\#1 ( $1.086 \mathrm{mmol} / \mathrm{g}$ ) (Table 2), which correlates with the results of their oxidation degrees representing by $\mathrm{O} / \mathrm{C}$ values in Table 1 . We also observed that the BET SSA of IL-C\#1 $\left(8.032 \mathrm{~m}^{2} / \mathrm{g}\right)$ is about 16.39 times than that of ILC\#2 (0.49 $\left.\mathrm{m}^{2} / \mathrm{g}\right)$, as illustrated in Fig. 5 , but it seems that the surface area cannot determine the water holding capacity of coal surface specifically at primary adsorption stage. Further, the measurement results between IL-C\#2 and AB-C show that their SSAs have some considerable 


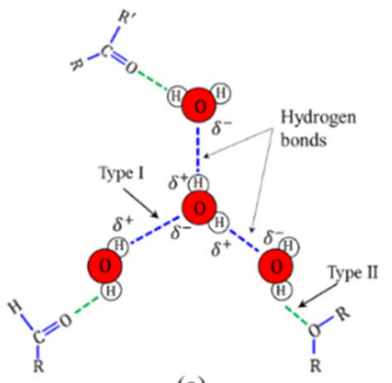

(a)

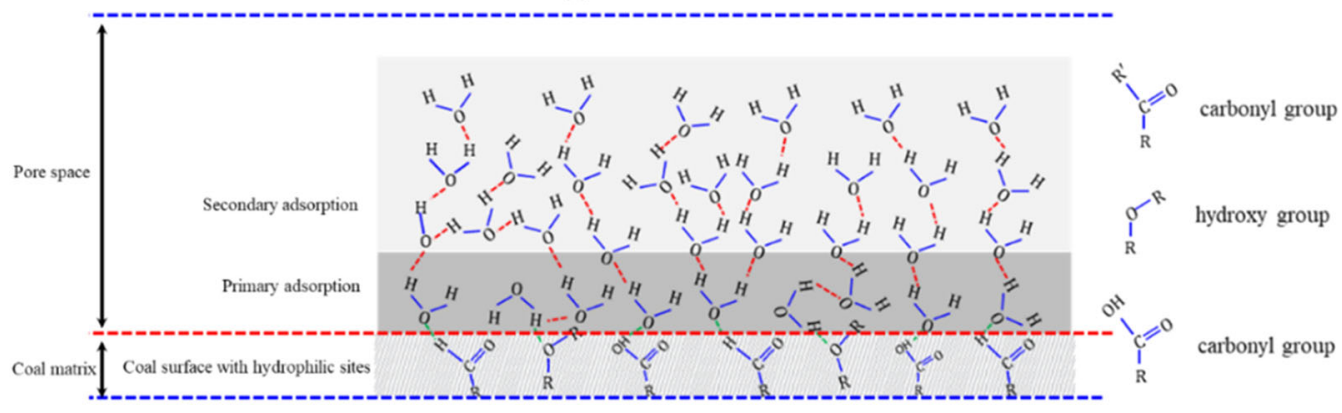

(b)

Fig. 7 Hydrogen bonds of primary adsorption on coal surface with hydrophilic sites and secondary adsorption formed on primary centers

difference ( 0.49 and $1.12 \mathrm{~m}^{2} / \mathrm{g}$, respectively), but the modeling results (at $25{ }^{\circ} \mathrm{C}$ ) showed that the maximum water holding capacity at primary adsorption stage is $\sim 0.291 \mathrm{mmol} / \mathrm{g}$ of AB-C, which is $\sim 3.75$ times less than IL-C\#2 does $(\sim 1.090 \mathrm{mmol} / \mathrm{g})$. The big difference between these two coal samples can be attributed to the distinction of oxidation degrees, with $\mathrm{O} / \mathrm{C}$ value of IL-C\#2 $(\sim 0.18)$ is $\sim 4.49$ times than AB-C $(\sim 0.040)$. The observation can also be confirmed by comparing the results between IL-C\#1 and AB-C showing that IL-C\#1 has approximately 3.25 times of $\mathrm{O} / \mathrm{C}$ value than $\mathrm{AB}-\mathrm{C}$ coal, and its water holding capacity at primary adsorption stage $(\sim 1.086 \mathrm{mmol} / \mathrm{g})$ is $\sim 3.73$ times than the latter one $(\sim 0.291 \mathrm{mmol} / \mathrm{g})$. The above observations confirmed that the positive correlations between the oxidation degree and the maximum water holding capacity during the primary adsorption stage. The results also confirmed that even the water molecules firstly adsorbed on the coal surface sites but strictly the primary adsorption sites should be hydrophilic centers such as oxygen-containing functional groups, rather than all the surface sites. The results implicitly illustrate that the pore surface area may not be the determining parameter that controls water vapor sorption at least during the primary adsorption stage. However, the statement for the total water holding capacity should be carefully extrapolated without further analyzing the secondary adsorption stage.

Based on the phenomenological Dubinin-Serpinsky approach, the secondary adsorption capacity of water vapor is quantified in in Eq. (2). The total amount of water vapor uptake combing the primary and secondary adsorptions can be calculated by Eq. (3). To evaluate the factors influencing the secondary adsorption, the contribution of secondary adsorption on total sorption isotherm can be computed by subtracting the primary adsorption quantity (Eq. (1)) from Eq. (3). For simplification, we used the maximum primary adsorption amount $\left(m_{\mathrm{L}}\right)$ quantified theoretically to represent the contribution of primary adsorption to the total water vapor uptake in this study. Taking $30{ }^{\circ} \mathrm{C}$ for example, as shown in Table 2, the primary adsorption capacity for IL-C\#1 and IL-C\#2 and AB-C coal are estimated as $1.330,1.347$, and $0.293 \mathrm{mmol} / \mathrm{g}$, respectively. If we examined the total water vapor uptake at relative humidity of $95 \%$, these three coal samples have the adsorbed amounts of water vapor of $9.220,4.550,0.788 \mathrm{mmol} / \mathrm{g}$, respectively. Correspondingly, the modeled amounts of secondary adsorptions in these three coal samples at this relative humidity are about $7.890,3.203$ and $0.495 \mathrm{mmol} / \mathrm{g}$, respectively. For both IL-C\#1 and IL-C\#2, they almost have the similar primary adsorption capacities, but the secondary adsorption constituting by the formation of water clusters or even pore filling shows an apparent difference and IL-C\#1 is estimated to be 2.46 times of IL$\mathrm{C \# 2}$. The secondary adsorption process accommodating both formation of water cluster and/or pore filling intrinsically occurs within the confined space provided by the pore structure/network. Thus, the PSD and the pore volume can influence the uptake process of water vapor. The cumulative pore volume of IL-C\#1 is $\sim 0.0137 \mathrm{~cm}^{3} / \mathrm{g}$, which is about 9.79 times than that of IL-C\#2 does $(0.0014$ 

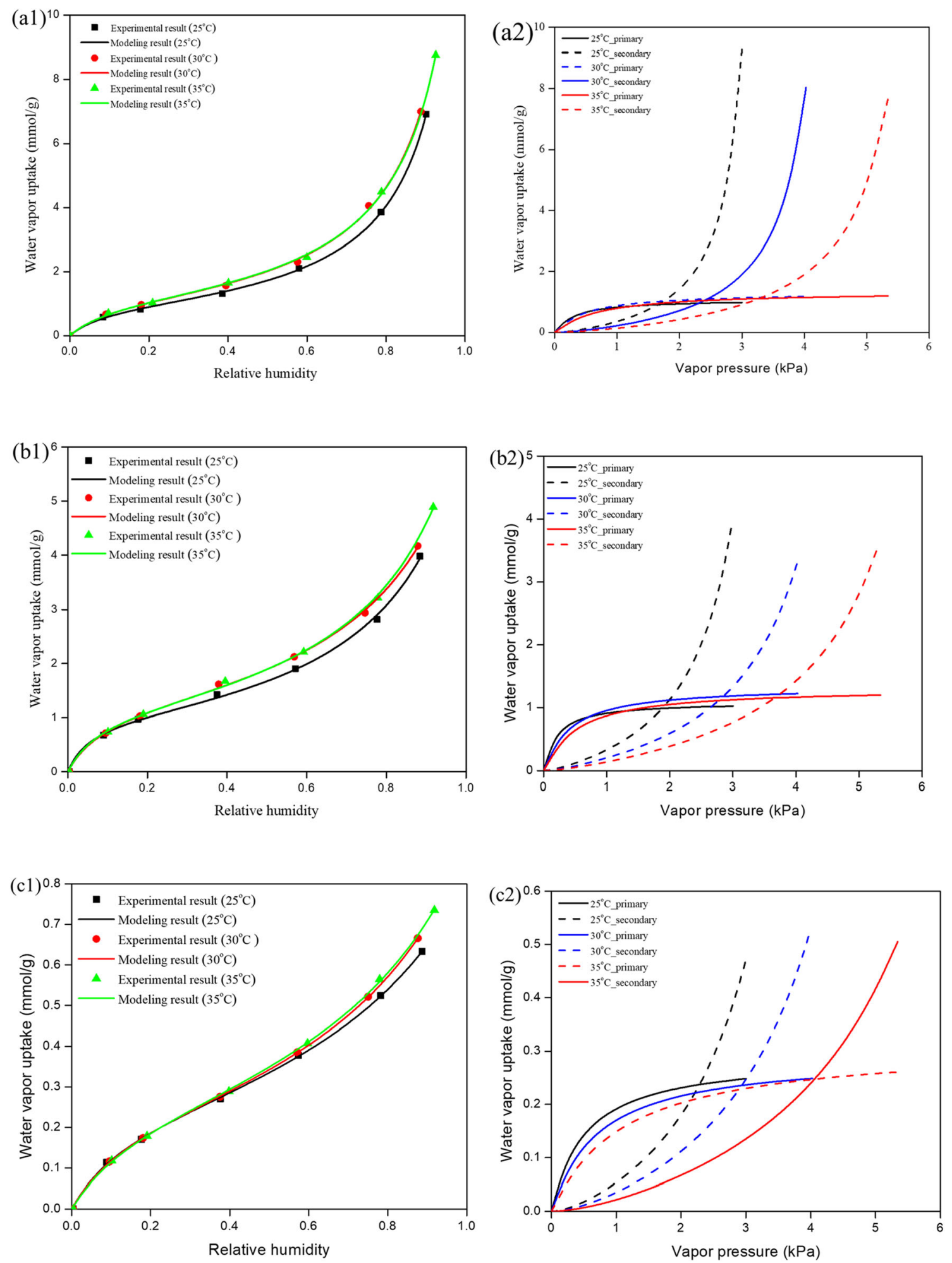

Fig. 8 Comparisons between the experiment data and modeling results: a1 and a2 IL \#1; b1 and b2 IL-C\#2; c1 and c2 AB-C

$\mathrm{cm}^{3} / \mathrm{g}$ ). Here the pore volume difference between these two coal samples shows positive relationship with their water holding capacities ( $\sim 2.46$ times difference). By comparing the secondary adsorption results between IL-C\#2 and
AB-C coal, IL-C\#2 $(3.203 \mathrm{mmol} / \mathrm{g})$ is about 6.47 times than that of the AB-C $(0.495 \mathrm{mmol} / \mathrm{g})$. Interestingly, the cumulative pore volume for pore sizes determined by liquid nitrogen adsorption in IL-C\#2 $\left(0.0014 \mathrm{~cm}^{3} / \mathrm{g}\right)$ is almost 
Table 2 Modeling results

\begin{tabular}{lllllll}
\hline $\begin{array}{l}\text { Sample } \\
\text { number }\end{array}$ & Coal rank & \multirow{2}{*}{$\begin{array}{l}\text { Temperature } \\
\left({ }^{\circ} \mathrm{C}\right)\end{array}$} & \multicolumn{4}{l}{ Model coefficients } \\
\cline { 4 - 7 } & & & $m_{\mathrm{L}}$ & $R_{\mathrm{L}}$ & $c$ & $R^{2}$ \\
\hline IL-C\#1 & Sub- & 25 & 1.086 & 0.100 & 0.952 & 0.99 \\
& bituminous & 30 & 1.330 & 0.121 & 0.938 & 0.99 \\
& & 35 & 1.348 & 0.123 & 0.933 & 0.99 \\
IL-C\#2 & Sub- & 25 & 1.090 & 0.062 & 0.839 & 0.99 \\
& bituminous & 30 & 1.347 & 0.096 & 0.805 & 0.99 \\
& & 35 & 1.350 & 0.100 & 0.800 & 0.99 \\
AB-C & Low volatile & 25 & 0.291 & 0.164 & 0.730 & 0.98 \\
& bituminous & 30 & 0.293 & 0.169 & 0.721 & 0.99 \\
& & 35 & 0.315 & 0.197 & 0.706 & 0.99 \\
& & & & & & \\
\hline
\end{tabular}

same with that in AB-C $\left(0.002 \mathrm{~cm}^{3} / \mathrm{g}\right)$. The results between IL-C\#2 and AB-C demonstrate that the cumulative pore volume is not the decisive factor influencing the amount of secondary adsorption for these two coal samples, which implicitly elaborates the underlying mechanism that the primary adsorption plays a decisive role in determining the sorption centers for the formation of water clusters during the secondary adsorption stage.

Based on the modeling regressed results of $m_{\mathrm{L}}, R_{\mathrm{L}}$ and $c$, the contributions of primary and secondary adsorptions to the total adsorption isotherm were calculated and plotted with respect to water vapor pressure in Fig. 8a2, b2 and c2. Under the same temperature, the results shown that the primary adsorption non-linearly increases with vapor pressure increases but the primary adsorption will reach its maximum capacity, which is controlled by Eq.(1). Simultaneously, the secondary adsorption will start after the monomolecular coverage is achieved during the primary adsorption stage. At relatively lower relative humidity, the primary adsorption dominates the process of water vapor uptake, while the secondary adsorption will play the decisive role in determining the final/total equilibrium amount of water vapor adsorption at high relative humidity. It is apparent that the temperature has considerable influence on the entire process. More precisely, as the increase of temperature, the movement of water molecule is enhanced resulting in that partial water molecules have enough energy to get rid of the attraction force between water molecules. The escaped water molecules decrease moisture amount at the given equilibrium relative humidity. At the same time, the higher temperature has limited effects on primary adsorption process, which is mainly due to the stronger chemical H-binding energy cannot be overcame by the increase molecular energy.

\subsubsection{Coal-water interaction process derived from isosteric heat of adsorption}

Previous studies shown that thermodynamically adsorption is an exothermic process and the sorption capacity decreases with increasing temperature because of a higher ordered adsorbed state.The isosteric heat of adsorption depends on the surface chemistry and the pore structure. The isosteric heat of water vapor adsorption can be used to evaluate the energy of interaction or intermolecular bonding between water molecules and solid surfaces. For water vapor sorption on coal, the presence of oxygen-containing functional provides higher energetic sorption sites, which are preferentially occupied by water molecules. The strong hydrogen bonding energy between the functional groups and water molecules can produce higher isosteric heat of sorption by comparing with the latent heat of bulk water condensation $(45 \mathrm{~kJ} / \mathrm{mol}$ at a surface coverage up to $10 \%)$. In this study, the isosteric heat of sorption was estimated by Eq. (13). The parameters $q_{\mathrm{L}}$ and $q_{0}$ were fitted based on Eqs. (9) and (10), and the modeled data in Table 2. The isosteric heats of adsorption (Fig. 9) decrease as water vapor uptake increase for all the samples, and which means an exothermic process. Taking the temperature of $25^{\circ} \mathrm{C}$ for example, the isosteric heats of adsorption for IL-C\#1 and IL-C\#2, and AB-C range from $\sim 59.1$ to $45.7 \mathrm{~kJ} / \mathrm{mol}$, from $\sim 76.2$ to $48.2 \mathrm{~kJ} / \mathrm{mol}, 58.6$ to $47.3 \mathrm{~kJ} / \mathrm{mol}$ as water vapor uptakes increase, respectively. At lower water adsorption uptake, the hydrogen bonding energy between the water molecules and solid matrix surface is strong and the isosteric heat of sorption is expected to be highat this stage, as illustrated in Fig. 9. In Fig. 9, as the increase of relative humidity, water molecules adsorb in the less active sites and multilayer adsorption occurs. The corresponding isosteric heat of water adsorption was found to have values very close to the latent heat of bulk water condensation. At a specified water adsorption uptake, the temperature difference can result in a small shift on the isosteric heat of adsorption curves, which is mainly due to the effects of temperature on the hydrogen bonding energy between the water molecules and solid matrix surface, and the interaction energy between water molecules.

\section{Discussion on colloidal gel structure of coal- water system as a function of relative humidity}

\subsection{Physical changes on colloidal gel structure of coal-water system}

Based on the experimental and modeling results in Sects. 3 and 4 as well as previous studies, moisture can be held in coals in several distinct forms mainly including sorbed 

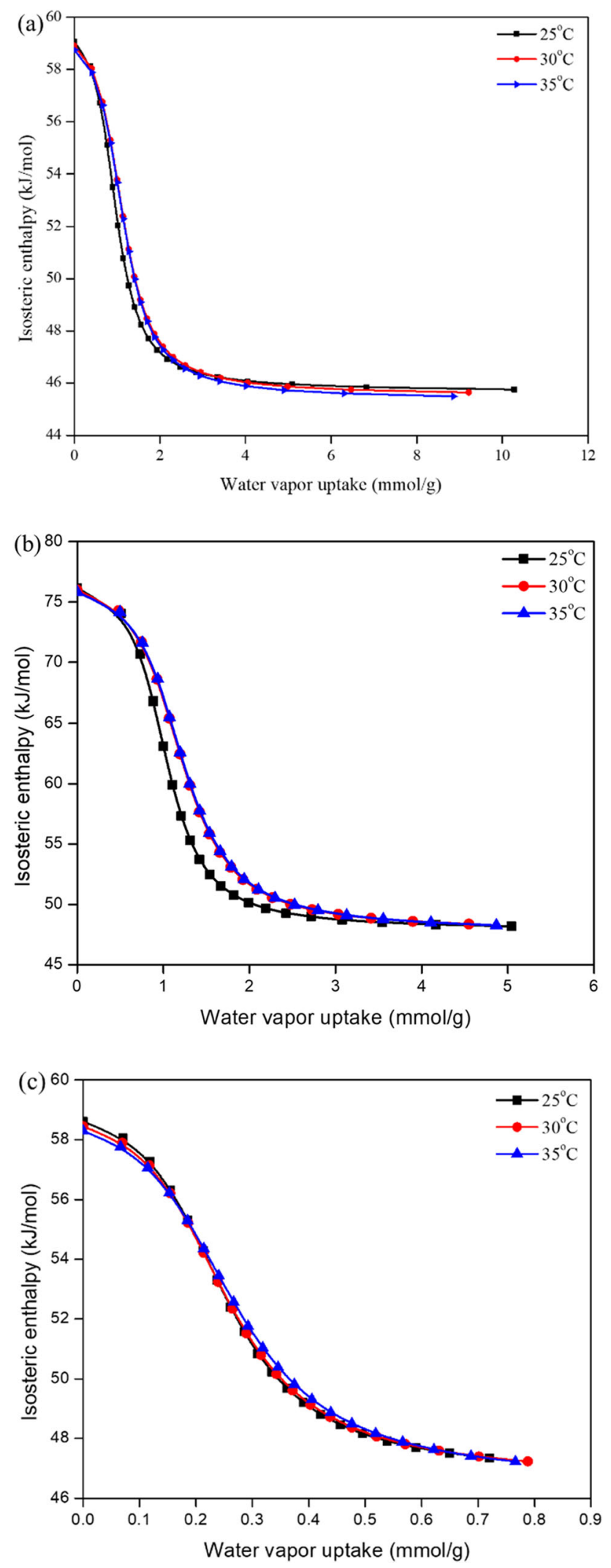

Fig. 9 Isosteric heat of adsorption of water vapor in IL-C\#1 water, capillary condensed water, and superficial free water (Deevi et al. 1987; Choi et al., 2001). Coal has a colloidal gel-like structure (Deevi and Suuberg 1987; Suuberg et al. 1993; Suuberg et al. 1994; Suuberg 1997) and coal-water system may be viewed as a colloidal gel that can shrink and swell in response to moisture loss or gain is well established and studied (Suuberg et al. 1993; Suuberg et al. 1994; Gorbaty 1978). Figure 10 shows the volumetric phase distribution of coal-water system as a function of relative humidity. The diagram ideally applies to relative volume changes on colloidal gel structure of coal-water system from initial dry condition ( 0 relative humidity) to the normal saturated condition ( $100 \%$ relative humidity). At the initial dry condition (point $A$ ), the coal-water system only contains dry solid coal matrix and open porosity volume. As relative humidity increases, moist air enters/fills the open fracture/pore space and almost simultaneously partial water molecules are held by hydrogenbonding sites on the solid matrix surface in adsorbed phase (point $B$ ). As the relative humidity continuously increases, those adsorbed water molecules occupied on primary sites are considered as the secondary centers for the formation of water aggregates or clusters. Also, water in capillary condensed phase will be formed in narrow pores at relatively high relative humidity condition (point $C$ ). Due to the limited pore space in coal, the coal-water system will arrive at the normal equilibrium state (point $D$ ) at the normal $100 \%$ relative humidity. From Fig. 10, it is worth noting that the solid coal matrix will swell to some extent in response to moisture gain due to the colloidal gel-like structure of coal. To what extent are the physical changes

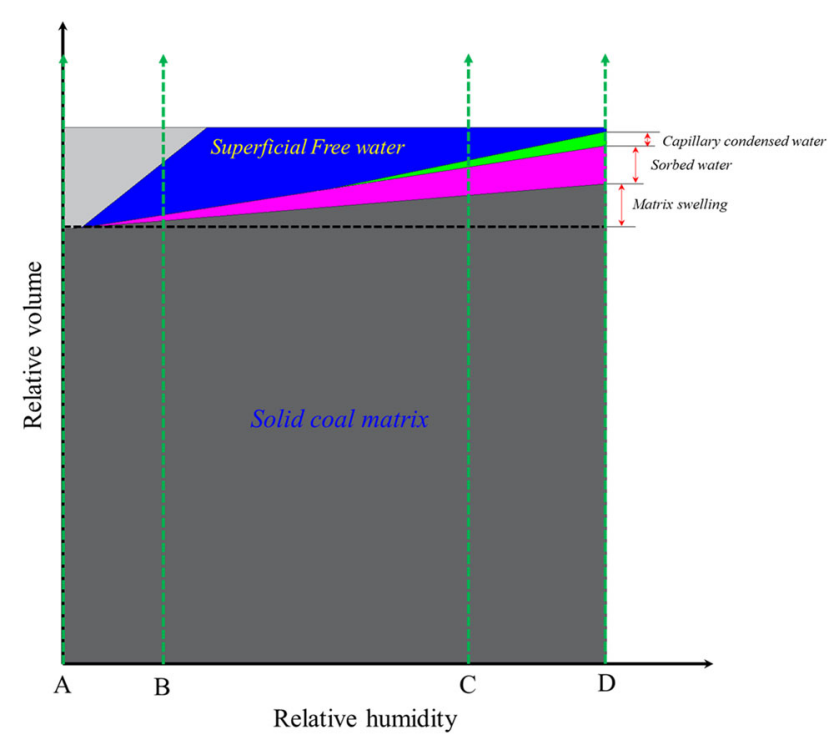

Fig. 10 Volumetric phase distribution of solid coal matrix and distinct forms of moisture as a function of relative humidity 
on colloidal gel structure of coal-water system as a function of relative humidity is of practical significance.

Deevi and Suuberg studied the physical changes accompanying drying of western U.S. lignites (Deevi and Suuberg 1987). The water desorption-adsorption isotherms were plotted in Fig. 11. In Fig. 11a, b, the Gascoyne and Freedom lignites show some irreversibility in the desorption-adsorption cycle. This was also observed for sub-bituminous coal samples in Fig. 6a1 and b1 in this study. Figure 11a1 and b1 shown that the adsorption-desorption cycles on dried coals (the first step of DVS test is drying condition, as shown in Fig. 3) and it was observed that the loops are closed at both the high and low ends of the relative humidity scale. However, in Fig. 11a and b, the desorption-adsorption cycle began with fresh coal fails to close at high end of the relative humidity scale. Behind the phenomenon is the evidence of an irreversible change in coal structure during initial drying stage. In addition, the effect of drying on the structure of a sub-bituminous coal was also studied by Gorbaty (1978). The results shown that drying sub-bituminous coal has a marked effect on its
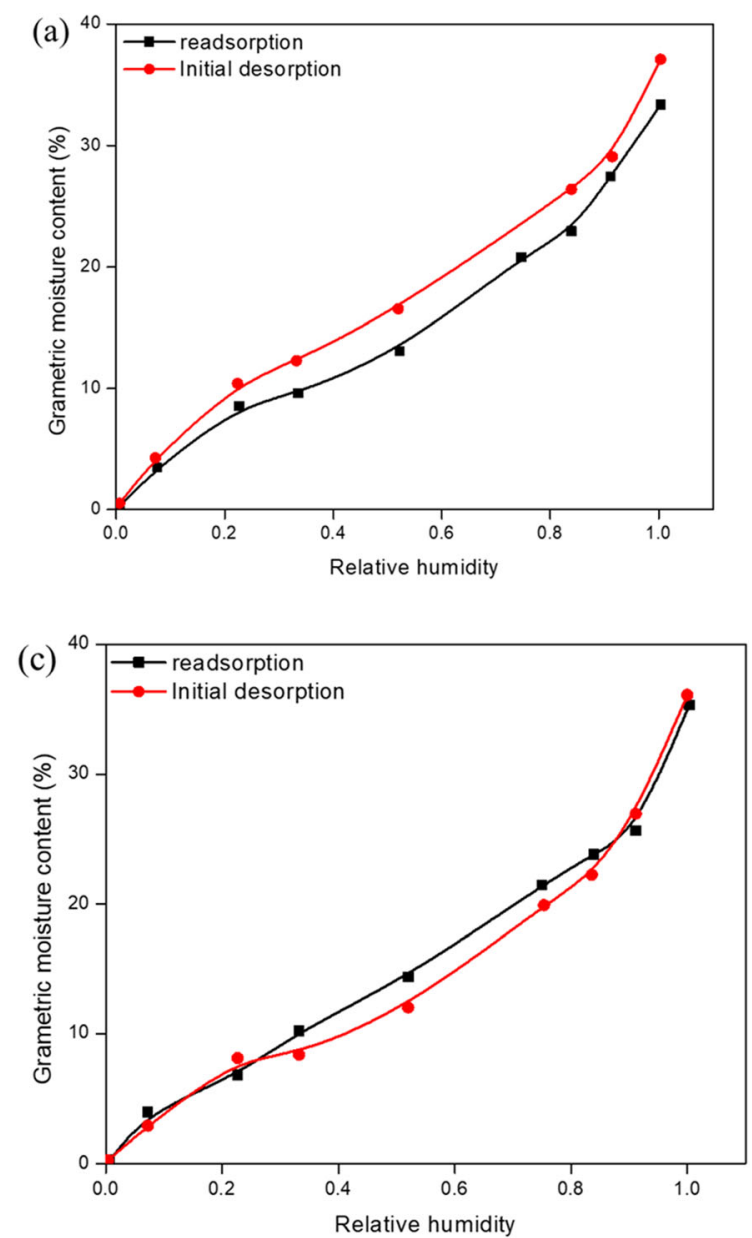

physical structure-the sub-bituminous coal exhibits collapse behavior and some collapsed are irreversible, which results in decreased mass transport through coal particle.

To further study the pore collapse behavior upon drying, Deevi and Suuberg further measured the macroscopic shrinkages on larger cubic lignite samples from North Dakota (Deevi and Suuberg 1987). Subsequently, they compared the measured macroscopic shrinkages and the volumetric shrinkages calculated on the assumption that all pores are initially filed with water and any water removed has a specific volume of $1 \mathrm{~cm}^{3} / \mathrm{g}$, as shown in Fig. 12. It was apparent that for all samples there are at least some regions of relative humidity in which collapse occurs to an extent much greater than predicted only removal of bulk water.

Also, Deevi and Suuberg measured the volumetric reswelling on dried finely ground lignites based on the conventional solvent swelling technique (Deevi and Suuberg 1987). It shown that the shrinkages of all the four samples upon drying are only partly reversible. The irreversibility of the process manifests itself even during
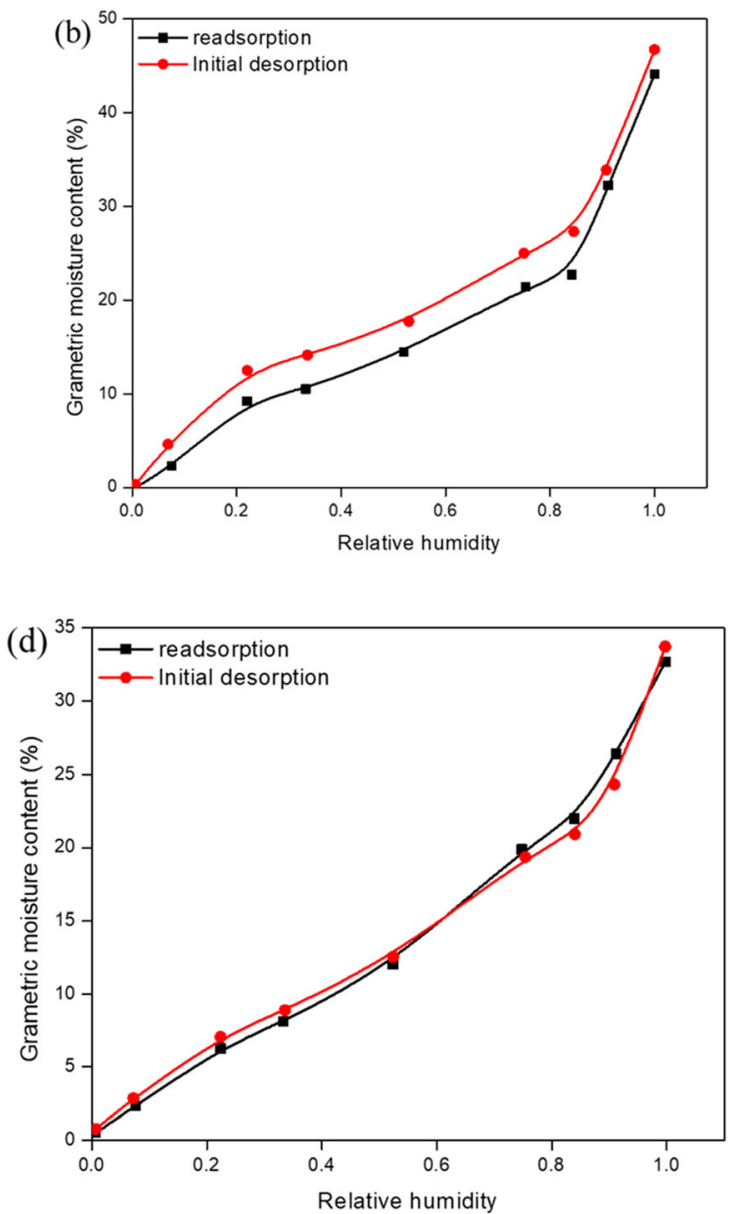

Fig. 11 Water desorption-readsorption isotherms of North Dakota lignites as a function of relative humidity (Deevi and Suuberg 1987). a Freedom sample. b Gascoyne sample. c Glenn Harold sample. d Beulah sample 

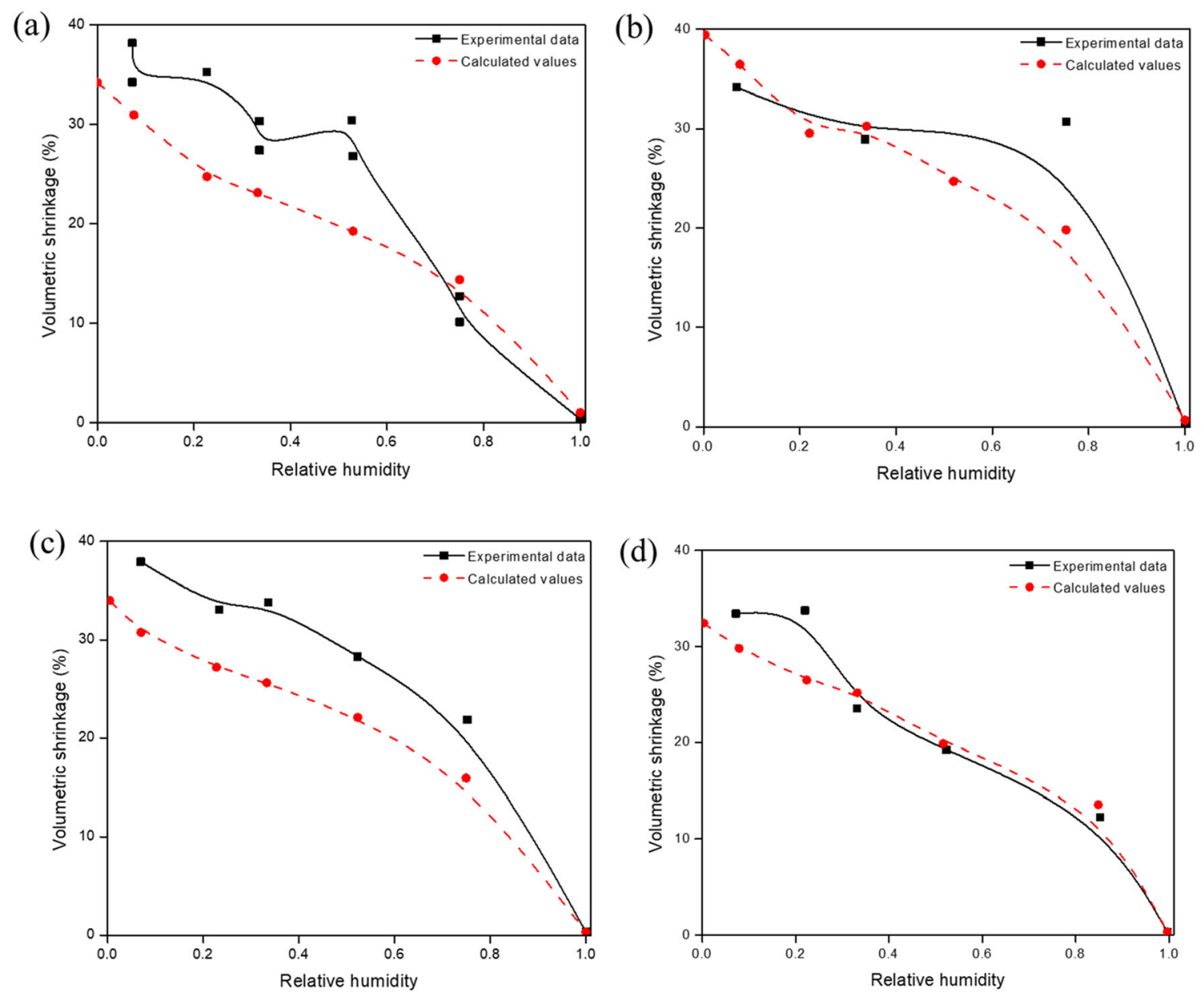

Fig. 12 Volumetric shrinkage of North Dakota lignites as a function of relative humidity (Deevi and Suuberg 1987). a Freedom sample. b Gascoyne sample. c Glenn Harold sample. d Beulah sample

partial drying (to relative humidity $=0.75$ ). Based on Kelvin equation and using the assumption of perfect wetting of the pore walls by water, the pores with diameter of $\sim 7 \mathrm{~nm}$ and larger at relative humidity of 0.75 are involved in the pore collapse scenario, which thus implies that irreversible shrinkage of the lignite samples is associated mainly with collapse of macroporosity and transitional porosity (Deevi and Suuberg 1987).

\subsection{Thermodynamics accompanying colloidal gel structure swelling/shrinkage}

The thermodynamics of the coal-water swelling process should consider various correlations of swellability with water properties (Suuberg et al. 1994). Suuberg et al. (1994) studied the solvent swelling thermodynamics of lignite in specifically interacting solvents. The results showed that the swelling property of coals is strongly determined by the electron-donating capacity of the solvents. Also, the swelling correlates with the heat of immersion of coals in solvents, and thus it appears that it is the enthalpy of interaction of specifically interacting solvents with surface functionalities in coal that mainly determines swelling behavior. There is generally a particular number of specific interaction sites in the coal that determine the maximum extent of swelling, though there is the possibility of nonspecific interactions contributing to further swelling, beyond this "titration end point (Suuberg et al. 1994). In this study, it can be concluded from Section 5.2.3 that the isosteric heat of water adsorption decreases as water vapor uptake increases, which was found to be close to the latent heat of bulk water condensation at higher relative humidity. The results confirmed that the primary adsorption is controlled by the stronger bonding energy while the interaction energy between water molecules during secondary adsorption stage is relatively weak. Thus, the fact that the coal structure undergoes what might be considered a "solvent swelling" in water means that the thermodynamics are complicated by the fact that internal bonding interactions within the coal are disrupted at the same time as new bonding interactions take place with the water molecules. 


\section{Summary and conclusions}

We conducted the coal and water vapor interaction experiment to investigate the water vapor sorption behavior of various coals. The relationships between water vapor sorption capacity and the surface chemistry of coal and coal pore structure were discussed in detail. Theoretically, a mechanism-based isotherm model was proposed to estimate the water vapor uptake at various relative humidity/ water vapor pressure, which is well validated with the experimental data. Further, the isosteric heat of water vapor sorption is modeled and determined by combining the Clausius-Clapeyron equation. The following major conclusions can be summarized:

(1) Oxidation degree feature of coal matrix was quantified by $\mathrm{O} / \mathrm{C}$ ratio through XPS technique. IL$\mathrm{C} \# 2$ has the highest oxidation degree (0.18) among three tested samples, followed by IL-C\#1 (0.13), and the minimum is AB-C coal of 0.04 .

(2) BET, SSA, PSD and cumulative pore volume were evaluated through low temperature nitrogen adsorption. The cumulative pore volumes for the three samples were $0.0137,0.0014$ and $0.002 \mathrm{~cm}^{3} / \mathrm{g}$, respectively. IL-C\#1 has highest SSA $\left(8.032 \mathrm{~m}^{2} / \mathrm{g}\right)$, followed by IL-C\#2 $\left(0.49 \mathrm{~m}^{2} / \mathrm{g}\right)$ and AB-C $\left(1.12 \mathrm{~m}^{2} /\right.$ g).

(3) SSA of coal is not the determining parameter that controls water vapor sorption at least during the primary adsorption stage. Oxidation degree dominates the primary adsorption, and togethering with the cumulative pore volume determine the secondary adsorption. Higher temperature has limited effects on primary adsorption process, which is mainly due to the stronger chemical H-binding energy is the energy barrier for water molecule detachment at high temperature.

(4) The isosteric heat of water adsorption decreases as water vapor uptake increases, which was found to be close to the latent heat of bulk water condensation at higher relative humidity. The results confirmed that the primary adsorption is controlled by the stronger bonding energy while the interaction energy between water molecules during secondary adsorption stage is relatively weak.

(5) Coal has a shrinkage/swelling colloidal structure with moisture loss/gain and it exhibits collapse behavior and some collapse are irreversible, which plays a significant role in determining moisture retention. The thermodynamics within coal-water interactions are complicated since internal bonding interactions within the coal are disrupted at the same time as new bonding interactions take place with the water molecules.

Acknowledgement This study was sponsored by the Open Fund Project Funded by State Key Laboratory of Coal Mine Disaster Dynamics and Control, Chongqing University (Grant \#2011DA105287-FW201903). We also want to thank the China Scholarship Council (CSC) for the financial support (Grant \#201806430028).

\section{Declarations}

Conflict of interest The authors declare that they have no known competing financial interests or personal relationships that could have appeared to influence the work reported in this paper.

Open Access This article is licensed under a Creative Commons Attribution 4.0 International License, which permits use, sharing, adaptation, distribution and reproduction in any medium or format, as long as you give appropriate credit to the original author(s) and the source, provide a link to the Creative Commons licence, and indicate if changes were made. The images or other third party material in this article are included in the article's Creative Commons licence, unless indicated otherwise in a credit line to the material. If material is not included in the article's Creative Commons licence and your intended use is not permitted by statutory regulation or exceeds the permitted use, you will need to obtain permission directly from the copyright holder. To view a copy of this licence, visit http://creativecommons. org/licenses/by/4.0/.

\section{References}

Ahamed MAA, Perera MSA, Matthai SK, Ranjith PG, Li DY (2019) Coal composition and structural variation with rank and its influence on the coal-moisture interactions under coal seam temperature conditions - A review article. J Pet Sci Eng 180:901-917. https://doi.org/10.1016/j.petrol.2019.06.007

Alduchov OA, Eskridge RE, Climatic N, Oceanic N (1996) Improved Magnus form approximation of saturation vapor pressure. J Appl Meteorol 35:601-609

Allardice DJ, Evans DG (1971) The brown coal/water system: Part 2. Water sorption isotherms on bed-moist Yallourn brown coal. Fuel 50:236-253. https://doi.org/10.1016/0016-2361(71)90014-7

Anderson RB (1946) Modifications of the Brunauer, emmett and teller equation. J Am Chem Soc 68:686-691. https://doi.org/10. 1021/ja01208a049

Babu JS, Sathian SP (2011) The role of activation energy and reduced viscosity on the enhancement of water flow through carbon nanotubes. J Chem Phys. https://doi.org/10.1063/1.3592532

Barton SS, Evans MJB, MacDonald JAF (1994) Adsorption of water vapor on nonporous carbon. Langmuir 10:4250-4252. https:// doi.org/10.1021/la00023a055

Behm RJ (2016) Interaction of a self-assembledionic liquid layer with graphite 0001. A Combin Exp Theoret Study. https://doi.org/10. 1021/acs.jpclett.5b02449

Bolt GH (1956) Physico-chemical analysis of the compressibility of pure clays. Geotechnique 6:86-93. https://doi.org/10.1680/geot. 1956.6.2.86

Brennan, J. K.; Bandosz, T. J.; Thomson, K. T.; Gubbins KE (2001) Water in porous carbons. Colloids and surfaces. Physico- Chem Eng Asp 187:187-188, 539-568 
Brunauer S, Emmett PH, Teller E (1938) Adsorption of gases in multimolecular layers. J Am Chem Soc 60:309-319. https://doi. org/10.1021/ja01269a023

Busch A, Gensterblum Y (2011) CBM and $\mathrm{CO}_{2}$-ECBM related sorption processes in coal: a review. Int $\mathrm{J}$ Coal Geol 87:49-71. https://doi.org/10.1016/j.coal.2011.04.011

Charrière D, Behra P (2010) Water sorption on coals. J Colloid Interface Sci 344:460-467. https://doi.org/10.1016/j.jcis.2009. 11.064

Choi JG, Do DD, Do HD (2001) Surface diffusion of adsorbed molecules in porous media: monolayer, multilayer, and capillary condensation regimes. Ind Eng Chem Res 40:4005-31

Crosdale PJ, Moore TA, Mares TE (2008) Influence of moisture content and temperature on methane adsorption isotherm analysis for coals from a low-rank, biogenically-sourced gas reservoir. Int J Coal Geol 76:166-174. https://doi.org/10.1016/ j.coal.2008.04.004

Dacey JR, Clunie JC, Thomas DG (1958) The adsorption of water by Saran charcoal. Trans Faraday Soc 54:250-256. https://doi.org/ $10.1039 /$ tf9585400250

de Boer JH (1953) The dynamical character of adsorption

Deevi SC, Suuberg EM (1987) Physical changes accompanying drying of western US lignites. Fuel 66:454-60

Dubinin MM, Zaverina ED, Serpinsky SV (1955) Trans Faraday Soc. 1760

Fan L, Ma X (2018) A review on investigation of water-preserved coal mining in western China. Int J Coal Sci Technol 5:411-416. https://doi.org/10.1007/s40789-018-0223-4

Fan L, Ma L, Yu Y, Wang S, Xu Y (2019) Water-conserving mining influencing factors identification and weight determination in northwest China. Int J Coal Sci Technol 6:95-101. https://doi. org/10.1007/s40789-018-0233-2

Freeman GB, Reucroft PJ (1979) Adsorption of $\mathrm{HCN}$ and $\mathrm{H}_{2} \mathrm{O}$ vapor mixtures by activated and impregnated carbons. Carbon 17:313-316. https://doi.org/10.1016/0008-6223(79)90001-0

Furmaniak S, Gauden PA, Terzyk AP, Rychlicki G (2008) Water adsorption on carbons - Critical review of the most popular analytical approaches. Adv Colloid Interface Sci 137:82-143. https://doi.org/10.1016/j.cis.2007.08.001

Giroux L, Charland JP, MacPhee JA (2006) Application of thermogravimetric Fourier transform infrared spectroscopy (TG-FTIR) to the analysis of oxygen functional groups in coal. Energy and Fuels 20:1988-1996. https://doi.org/10.1021/ef0600917

Gorbaty ML (1978) Effect of drying on the adsorptive properties of subbituminous coal. Fuel 57:796

Gregg SJ, Sing KSW (1982). Adsorption Surface Area and Porosity. 2nd edition. Acad Press, New York

Guggenheim EA (1966) Applications of statistical mechanics

Huang Q, Liu S, Wang G, Wu B, Zhang Y (2019) Coalbed methane reservoir stimulation using guar-based fracturing fluid: a review. J Nat Gas Sci Eng 66:107-125. https://doi.org/10.1016/j.jngse. 2019.03.027

Huang Q, Liu S, Wang G, Wu B, Yang Y, Liu Y (2019) Gas sorption and diffusion damages by guar-based fracturing fluid for CBM reservoirs. Fuel 251:30-44. https://doi.org/10.1016/j.fuel.2019. 04.031

Joubert JI, Grein CT, Bienstock D (1974) Effect of moisture on the methane capacity of American coals. Fuel 53:186-191. https:// doi.org/10.1016/0016-2361(74)90009-X

Kadioğlu Y, Varamaz M (2003) The effect of moisture content and air-drying on spontaneous combustion characteristics of two Turkish lignites. Fuel 82:1685-1693. https://doi.org/10.1016/ S0016-2361(02)00402-7

Kaji R, Muranaka Y, Otsuka K, Hishinuma Y (1986) Water absorption by coals: effects of pore structure and surface oxygen. Fuel 65:288-291. https://doi.org/10.1016/00162361(86)90023-2

Kovtun A, Jones D, Dell'Elce S, Treossi E, Liscio A, Palermo V (2019) Accurate chemical analysis of oxygenated graphenebased materials using X-ray photoelectron spectroscopy. Carbon 143:268-275. https://doi.org/10.1016/j.carbon.2018.11.012

Kraehenbuehl F, Quellet C, Schmitter B, Stoeckli HF (1986) The relationship between immersion calorimetry and the parameters of the water adsorption isotherm on active carbons. J Chem Soc Faraday Trans 1 Phys Chem Condens Phases 82: 3439-3445. https://doi.org/10.1039/F19868203439

Langmuir I (1916) The constitution and fundamental properties of solids and liquids. Part I. Solids J Am Chem Soc 38:2221-2295. https://doi.org/10.1021/ja02268a002

Li W, Wang Q, Liu S, Pei Y (2018) Study on the creep permeability of mining-cracked $\mathrm{N}_{2}$ laterite as the key aquifuge for preserving water resources in Northwestern China. Int J Coal Sci Technol 5:315-327. https://doi.org/10.1007/s40789-018-0214-5

Liu L, Tan S, Horikawa T, Do DD, Nicholson D, Liu J (2017) Water adsorption on carbon - A review. Adv Colloid Interface Sci 250:64-78. https://doi.org/10.1016/j.cis.2017.10.002

Liu A, Kai W, Jie Z, Du F (2018) Relative permeability of gas for unconventional reservoirs. Transp Porous Media 124:289-307. https://doi.org/10.1007/s11242-018-1064-8

Liu A, Liu S, Wang G, Sang G (2020) Modeling of coal matrix apparent strains for sorbing gases using a transversely isotropic approach. Rock Mech Rock Eng. https://doi.org/10.1007/ s00603-020-02159-3

Liu A, Liu S, Wang G, Elsworth D (2020a) Predicting fugitive gas emissions from gob-to-face in longwall coal mines: coupled analytical and numerical modeling. Int $\mathrm{J}$ Heat Mass Transf 150:119392. https://doi.org/10.1016/j.ijheatmasstransfer.2020. 119392

Liu A, Liu P, Liu S (2020b) Gas diffusion coefficient estimation of coal: a dimensionless numerical method and its experimental validation. Int J Heat Mass Transf 162:120336. https://doi.org/ 10.1016/j.ijheatmasstransfer.2020.120336

Liu A, Liu S, Hou X, Liu P (2020c) Transient gas diffusivity evaluation and modeling for methane and helium in coal. Int $\mathbf{J}$ Heat Mass Transf 159:120091. https://doi.org/10.1016/j.ijheat masstransfer.2020.120091

Liu A, Liu P, Liu S (2020d) Gas diffusion coefficient estimation of coal : A dimensionless numerical method and its experimental validation. Int J Heat Mass Transf 162:120336. https://doi.org/ 10.1016/j.ijheatmasstransfer.2020.120336

Mahajan OP (1991) $\mathrm{CO}_{2}$ surface area of coals: the 25-year paradox. Carbon 29:735-742. https://doi.org/10.1016/00086223(91)90010-G

Mahajan OP, Walker PL (1971) Water adsorption on coals. Fuel 50:308-317. https://doi.org/10.1016/0016-2361(71)90019-6

McCutcheon AL, Barton WA, Wilson MA (2003) Characterization of water adsorbed on bituminous coals. Energy Fuel 17:107-112. https://doi.org/10.1021/ef020101d

Murata S, Hosokawa M, Kidena K, Nomura M (2000) Analysis of oxygen-functional groups in brown coals. Fuel Process Technol 67:231-243. https://doi.org/10.1016/S0378-3820(00)00102-8

Nishino J (2001) Adsorption of water vapor and carbon dioxide at carboxylic functional groups on the surface of coal. Fuel 80:757-764. https://doi.org/10.1016/S0016-2361(00)00136-8

Ogunsola OI (1993) Thermal upgrading effect on oxygen distribution in lignite. Fuel Process Technol 34:73-81. https://doi.org/10. 1016/0378-3820(93)90062-9

Pan Z, Connell LD, Camilleri M, Connelly L (2010) Effects of matrix moisture on gas diffusion and flow in coal. Fuel 89:3207-3217. https://doi.org/10.1016/j.fuel.2010.05.038 
Sang G, Liu S, Zhang R, Elsworth D, He L (2018) Nanopore characterization of mine roof shales by SANS, nitrogen adsorption, and mercury intrusion: Impact on water adsorption/ retention behavior. Int J Coal Geol 200:173-185. https://doi. org/10.1016/j.coal.2018.11.009

Sang G, Liu S, Elsworth D (2019) Water vapor sorption properties of Illinois shales under dynamic water vapor conditions: experimentation and modeling. Water Resour Res 55:7212-7228. https://doi.org/10.1029/2019WR024992

Schafer HNS (1970) Carboxyl groups and ion exchange in low-rank coals. Fuel 49:197-213. https://doi.org/10.1016/00162361(70)90040-2

Seah MP (2001) Summary of ISO / TC 201 Standard: VII ISO 15472: 2001- surface chemical analysis - x-ray photoelectron spectrometers - calibration of energy scales https://doi.org/https://doi.org/ 10.1002/sia.1076

Smith JA, Ramandi HL, Zhang C, Timms W (2019) Analysis of the influence of groundwater and the stress regime on bolt behaviour in underground coal mines. Int J Coal Sci Technol 6:286-300. https://doi.org/10.1007/s40789-019-0246-5

Stach E, Mackowsky MT, TeichmÜller M (1982) Stach's textbook of coal petrology. GebrÜder borntraeger, Berlin Stuttgart

Susilawati R, Ward CR (2006) Metamorphism of mineral matter in coal from the Bukit Asam deposit, south Sumatra, Indonesia. Int J Coal Geol 68:171-95. https://doi.org/10.1016/j.coal.2006.02. 003

Suuberg EM (1997) Comments regarding the use of coal swelling to count hydrogen-bond cross-links in coals. Energy Fuel 11:1103-4

Suuberg EM, Otake Y, Yun Y, Deevi SC (1993) Role of moisture in coal structure and the effects of drying upon the accessibility of coal structure. Energy Fuel 7:384-92

Suuberg EM, Otake Y, Langner MJ, Leung KT, Milosavljevic I (1994) Coal macromolecular network structure analysis: solvent swelling thermodynamics and its implications. Energy Fuels $8: 1247-62$

Švábová M, Weishauptová Z, Přibyl O (2011) Water vapour adsorption on coal. Fuel 90:1892-1899. https://doi.org/10.1016/ j.fuel.2011.01.005

Tang X, Ripepi N, Valentine KA, Keles C, Long T, Gonciaruk A (2017) Water vapor sorption on marcellus shale: measurement, modeling and thermodynamic analysis. Fuel 209:606-614. https://doi.org/10.1016/j.fuel.2017.07.062

Thommes M, Kaneko K, Neimark AV, Olivier JP, RodriguezReinoso F, Rouquerol J et al (2015) Physisorption of gases, with special reference to the evaluation of surface area and pore size distribution (IUPAC Technical Report). Pure Appl Chem 87:1051-1069

Tiwari B, Ajmera B (2011) Consolidation and swelling behavior of major clay minerals and their mixtures. Appl Clay Sci 54:264-273. https://doi.org/10.1016/j.clay.2011.10.001

Van der Merwe D, Campbell QP (2002) An investigation into the moisture absorption properties of thermally dried South African fine coal. J South African Inst Min Metall 102:417-419

van Krevelen DW (1993) Coal: typology, physics, chemistry. Constitution, Elsevier Science, Amsterdom

Wan K, He Q, Miao Z, Liu X, Huang S (2016) Water desorption isotherms and net isosteric heat of desorption on lignite. Fuel 171:101-107. https://doi.org/10.1016/j.fuel.2015.12.054

Wang K, Liu A, Zhou AT (2017) Theoretical analysis of influencing factors on resistance in the process of gas migration in coal seams. Int J Min Sci Technol 27:315-319. https://doi.org/10. 1016/j.ijmst.2017.01.011

Ward CR (2002) Analysis and significance of mineral matter in coal seams. Int J Coal Geol 50:135-168. https://doi.org/10.1016/ S0166-5162(02)00117-9

Ward CR (2016) Analysis, origin and significance of mineral matter in coal: an updated review. Int J Coal Geol 165:1-27. https://doi. org/10.1016/j.coal.2016.07.014

Yang Y, Liu S (2020) Laboratory study of cryogenic treatment induced pore-scale structural alterations of Illinois coal and their implications on gas sorption and diffusion behaviors. J Pet Sci Eng 194:107507. https://doi.org/10.1016/j.petrol.2020.107507

Yu J, Tahmasebi A, Han Y, Yin F, Li X (2013) A review on water in low rank coals: the existence, interaction with coal structure and effects on coal utilization. Fuel Process Technol 106:9-20. https://doi.org/10.1016/j.fuproc.2012.09.051

Zaldivar RJ, Adams PM, Nokes J, Kim HI (2017) Surface functionalization of graphenelike materials by carbon monoxide atmospheric plasma treatment for improved wetting without structural degradation degradation. J Vac Sci Technol B 10(1116/ 1):3695337

\section{Publisher's Note}

Springer Nature remains neutral with regard to jurisdictional claims in published maps and institutional affiliations. 